\title{
Three Dimensional Subsurface Structure beneath the Hino River Flat, South-East Shore of Lake Biwa, Central Japan
}

\author{
Tomoki Tsutsui \\ Geophysical Institute, Kyoto University, Kyoto 606, Japan
}

The subsurface structure of the Hino River flat, southeast shore of Lake Biwa, central Japan, has been surveyed with several seismic methods simultaneously, i.e., observations of microseisms, the Common Depth Point (CDP) profiling method and the Pseudo-Reflection Profiling (PRP) method.

In the first stage of the survey, a probable discontinuity of subsurface structure is detected from observations of microseisms along two linear arrays on the flat, and the difference in the basement rock depth on the western and eastern parts of the flat is roughly estimated from observed phase velocities of microseisms across a few two-dimensional arrays.

In the second stage, two small portions of the flat are surveyed with the CDP method in order to determine subsurface structure in more detail. Moreover, the PRP method, by using explosion seismograms, is invoked to supplement the coverage of CDP profiling method and to investigate three-dimensional subsurface structure beneath the flat.

The results are summarized as follows:

1. Unconsolidated sediments, Biwako- and Kobiwako-group, become thicker westward.

2. The A-horizon which appears in the CDP profile at the depth of $300 \mathrm{~m}$ is correlated with the layer boundary at the depth of $500 \mathrm{~m}$ in the sediment at a deep drilling site on the western margin of the flat.

3. The B-horizon which is correlated with the top of the basement rock has a westward dip with a north-southward strike to the west of the Hino River. Its depth difference between the eastern and western parts of the flat is estimated at about $400 \mathrm{~m}$. The dipping B-horizon is a part of the westward-facing wall of a valley along longitude $136^{\circ} \mathrm{E}$ which extends from offshore of the lake to the site. This valley seems to be a tectonic boundary that separates the seismic-quiescent area to the east from the seismic-active area to the west.

4. Another minor buried valley with ESE-WNW-ward strike exists to the south of the reflection lines around the Hino River.

5. A small hidden fault of west-side down type may exist near the Hino River.

Received July 9, 1990; Accepted February 3, 1991 


\section{Introduction}

The Hino River flat is a delta area beside Lake Biwa, central Japan. The flat facing Lake Biwa to the north is bounded by a terrace rim on the south, hills of Koto-Rhyolite around Ohmi-Hachiman city on the east, and the abandoned course of the Yasu River (north branch) on the west. The Hino River has reclaimed this area with its deposits.

The result of gravity survey by Horie et al. (1981) is shown in Fig. 1. A generally negative and gently northward dipping Bouguer anomaly is found over the Hino River flat. But a belt of a steep westward gradient of the Bouguer anomaly is more conspicuous with a north-southward strike around the estuary area of the river. From the shore, the belt can be traced northward to the west of the Oki-Shima Island (Ok) and southward about $5 \mathrm{~km}$ beneath the Hino River flat. It has been noted that a fault (apparently a

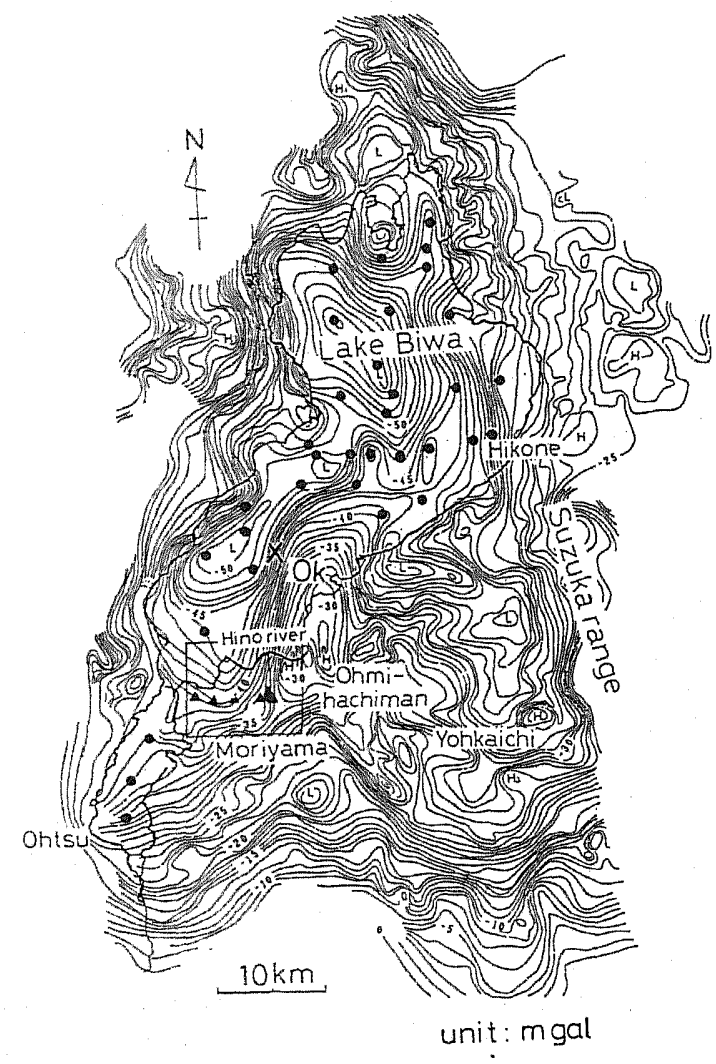

Fig. 1. The Bouguer anomaly map around Lake Biwa (after Horie et al., 1981). The solid circles are lake-bottom stations of gravity. A cross symbol indicates the location of the fault detected through multi-channel seismic profiling by Horie and Tanaka (1983). The rectangle is the target area in this study. The solid triangles within the rectangle indicate stations of refraction lines and the Hino River site. "Ok" in the lake indicates the Oki-Shima island. 


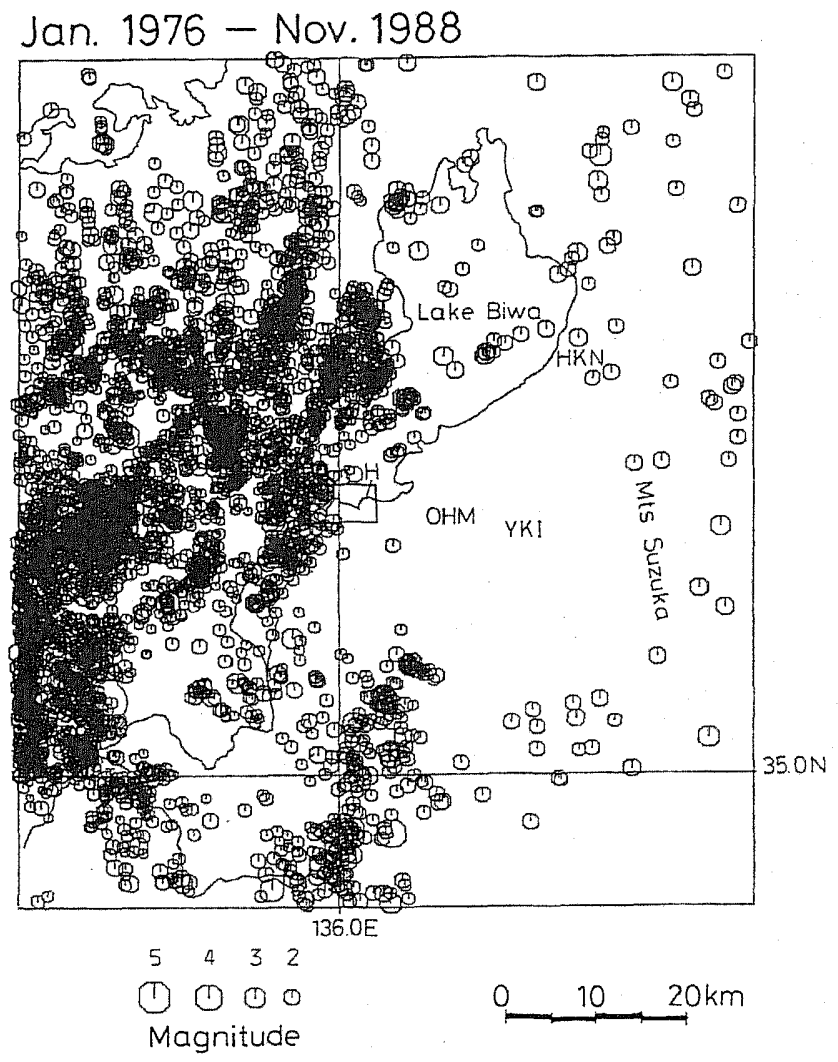

Fig. 2. A seismicity map of the region around Lake Biwa, January 1976-November 1988, by courtesy of Regional Center for Earthquake Prediction, Kyoto University. Note a remarkable quiescent area around Ohmi-Hachiman (OHM). HKN and YKI indicate Hikone city and Yohkaichi city, respectively. $\mathrm{H}$ is the estuary of the Hino River. The rectangle is the target area in this study.

normal type) was found on the northward extension of the steep gradient belt by Horie and Tanaka (1983) and Taishi et al. (1987) as indicated in Fig. 1 by a cross. This steep gradient belt of the Bouguer anomaly is considered to be the eastern boundary of the central basin in a basin system of Lake Biwa by Horie et al. (1981). The sedimentary structure of Kobiwako- and Biwako-group reflects the history of structural movement through the evolution of Lake Biwa. Thus the subsurface structure of this area is of importance from the geological point of view.

On the other hand, the Hino River flat is a part of the seismic-quiescent area which was pointed out by the Research Group of Seismicity around Lake Biwa (1977) from the earthquake observations taken over one year. Since then, this area has been calm for more than ten years as shown in Fig. 2 (by courtesy of Regional Center for Earthquake Prediction, Kyoto University). The quiescent area is located in the Koto- 
Cauldron area which was active in the late Cretaceous with $40 \mathrm{~km}$ of east-westward major axis and $20 \mathrm{~km}$ of south-northward minor axis (Nishikawa et al., 1983) around Ohmi-Hachiman city. A portion of the eastern part of the quiescent area is underlain by deposits of Kobiwako-group which is older than Yohkaichi formation and has been considered as the migration route of Lake Paleo-Biwa by Yokoyama (1979). Some of the western part of this quiescent area which corresponds to the basin of the present lake is filled with Biwako-group sediments which are younger than the Katata formation. Few active faults in the quiescent area are described by The Research Group for Active Faults (1980) probably because soft and thick sediments had prevented investigators from finding outcrops of any fault. However, this area is located in an active-subsidence area around Lake Biwa with about a thousand meters of vertical displacement over more than five million years, and it is an interesting issue for regional tectonics whether the low seismicity is only a temporal phenomenon in some seismic sequence or may be attributed to an intrinsic character of the lithosphere.

Prior to this study, a gravity survey over the whole basin of the lake (Horie et al., 1981) and a multi-channel seismic survey in the lake (Horie and Tanaka, 1983) were performed, and brought much important information about the evolution of Lake Biwa. Though the shallow subsurface structure beneath flats beside the lake holds the key information to estimate structural movement and a detailed Paleo-environmental history, no information except for a deep drilling and gravity survey has been obtained, and the details of the evolution of the lake are still veiled. Therefore, threedimensional seismic survey over flats will be useful in studying the tectonic history of this district over the past ages. Hence the Hino River flat, a western part of the Koto plain, is an interesting target for such a survey.

In this study, subsurface structure is investigated with seismic methods along survey lines across the Hino River flat as shown in Fig. 3. The observation of microseisms was employed in order to grasp the outline of the subsurface structure in the first stage of the survey. The observation consists of two approaches: One is spectral analysis of microseisms on linear arrays to locate discontinuities of subsurface structure, and another is phase-velocity analysis to estimate the depth structure on various parts of the flat.

In the next stage of the survey, Common Depth Point (CDP) profiling was employed for a more detailed survey along two survey lines (solid lines in Fig. 3) around the Hino River where the microseisms survey implied a discontinuity of basement rock. Moreover, Pseudo-Reflection Profiling (PRP) method was utilized along a dashed line and on a train of open triangles in Fig. 3 in order to supplement the coverage of CDP profiling and to delineate the three-dimensional structure. Explosion seismograms are used for this analysis.

The new method, PRP method, had many advantages in this study. For example, even a poor synchronous precision of time codes does not degrade the quality of the resulting profiles and alignment of the stations is not necessary. Compared with the CDP profiling method, these advantages reduce a great amount of the task usually involved in field work, even in three-dimensional cases. The scheme of this new method is given in Appendix and the details are described in Tsutsui (1990).

The details concerning microseisms measurement and CDP profiling have been 


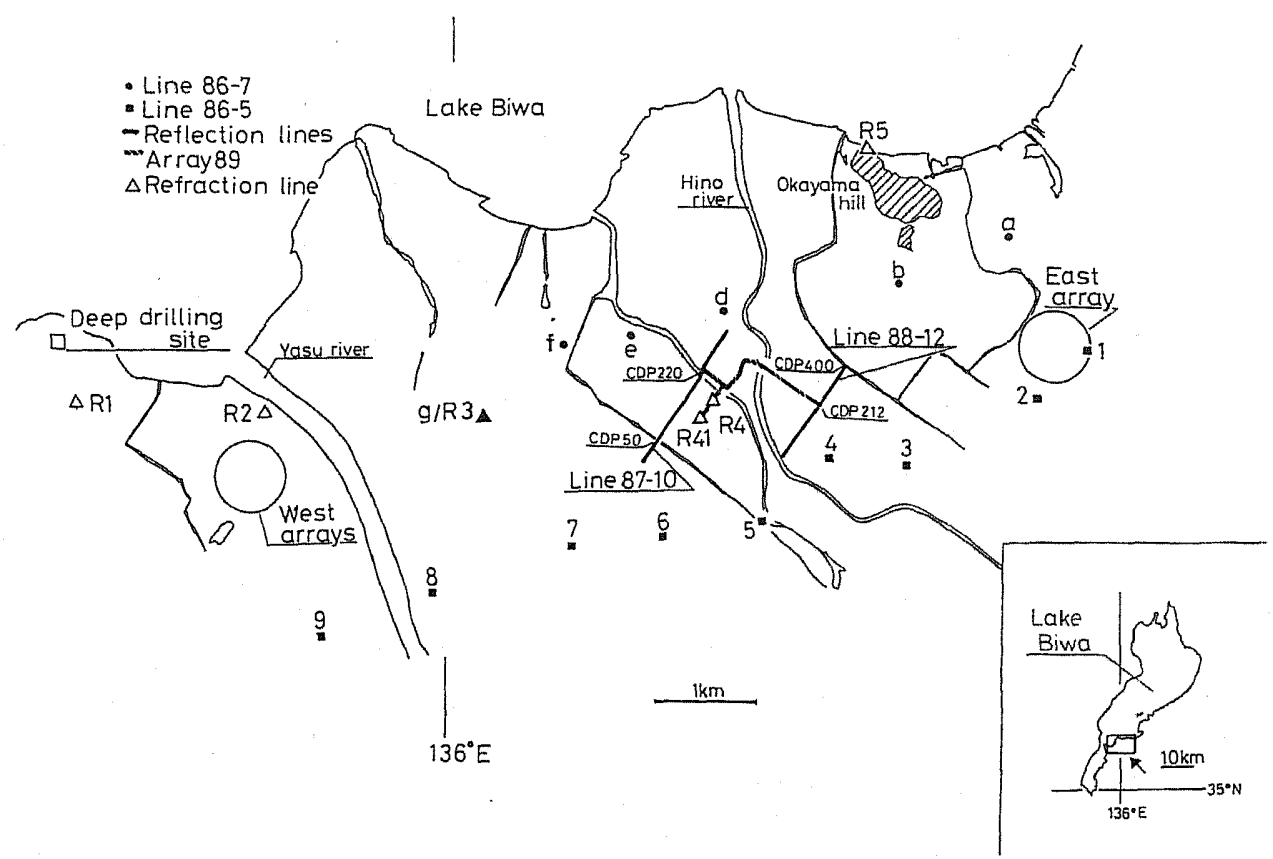

Fig. 3. Location of all seismic survey sites for this study over the Hino River flat. The open rectangle is the deep-drilling site after Yokoyama et al. (1979). Mean interval of the refraction stations is about $2 \mathrm{~km}$.

already described in Tsutsui and Kobayashi (1989) and Tsutsui et al. (1989). Therefore, in Secs. 2 and 3 of this paper, their main results are briefly reviewed and some new analysis are supplemented. Section 4 describes the results of the PRP method. On the basis of the foregoing results a three-dimensional subsurface structure model beneath the Hino River flat is constructed and its tectonic significance is discussed in Sec. 5.

\section{Observation of Microseisms}

\subsection{Variation of microseisms spectra along the linear arrays across the Hino River flat}

In order to estimate an approximate subsurface structure beneath the Hino River flat, Tsutsui and Kobayashi (1989) laid two linear arrays, Line 86-7 and Line 86-5, for the spectral analysis of microseisms, as shown in Fig. 3 with solid squares and triangles. Microseisms were observed with horizontal-motion seismometers (portable, long-period type) at most stations by mobile parties except for several fixed stations as reference. A common fixed station, OBS-4, was included in both linear arrays at which observations were made on different nights.

The spectral ratios of the observed microseisms at each station to that of the reference station (OBS-4) in the same time period are arranged in order of west to east in Fig. 4(a) and (b) for Line 86-5 and Line 86-7, respectively. A clear systematic spectral difference is observed in the range of 0.2 to $0.5 \mathrm{~Hz}$ between the east and west sides of 

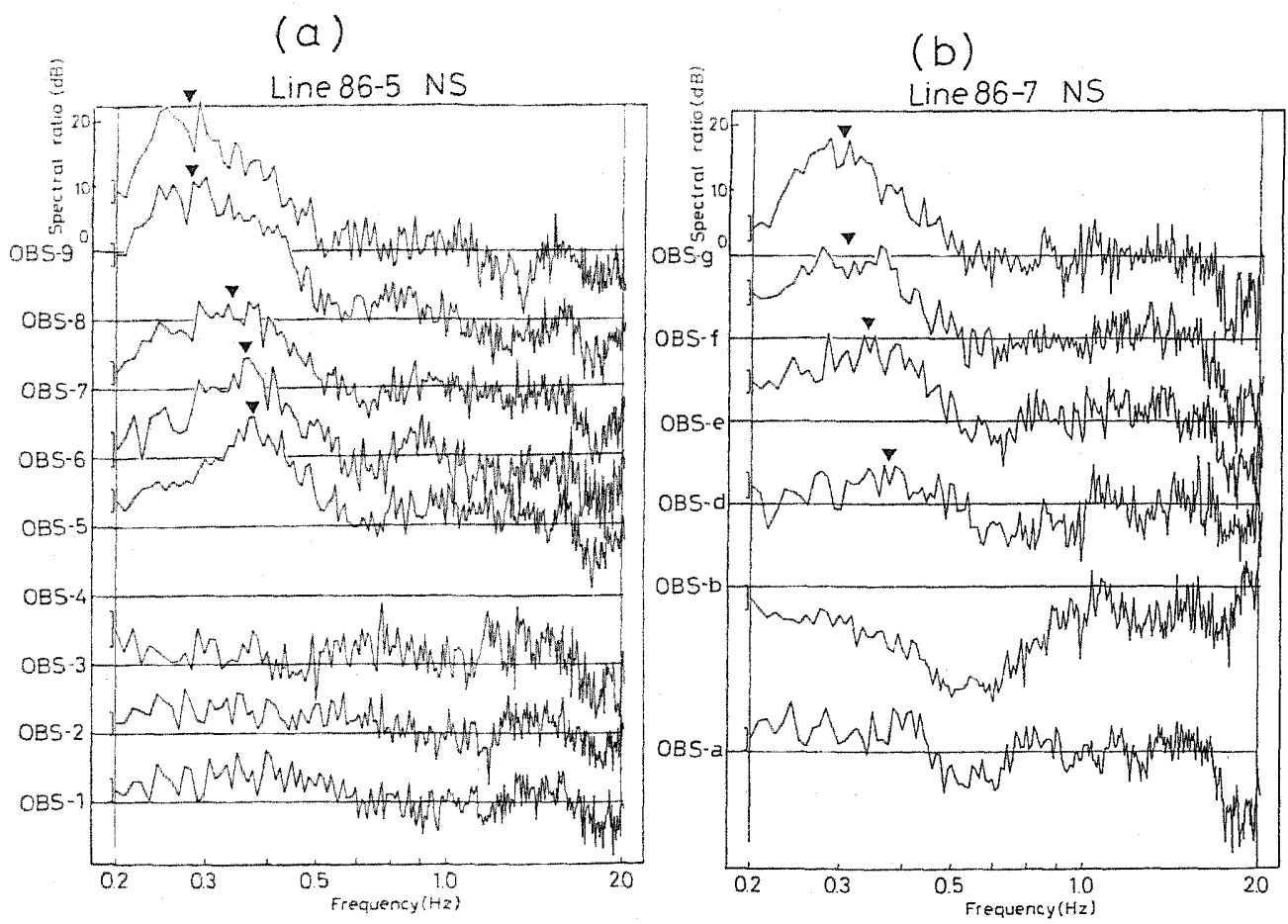

Fig. 4. Spectral ratios to the station OBS-4. (a) and (b) correspond to Line 86-5 and Line 86-7, respectively. The reversed triangles point to peaks in the spectra, and the bars at the left end of the spectra display $95 \%$ confidence interval. The spectra for the stations to the east of the Hino River have peaks below $0.5 \mathrm{~Hz}$.

the river. The transition zone of this spectral difference appears between OBS-4 and OBS-5 on Line 86-5, and OBS-b and OBS-e on Line 86-7 which were all placed around the Hino River. The peak frequencies of the spectral ratios become lower westwardly to the west of the river. It should be noted that this transition zone coincides with the steep-gradient belt of the Bouguer anomaly along the river.

Tsutsui and Kobayashi (1989) concluded that the systematic change of the spectral ratios in the frequency range of 0.2 to $0.5 \mathrm{~Hz}$ implies a discontinuity of subsurface structure around the Hino River, because the effect of temporal variation of incident microseisms into this area during observations is removed by the spectral ratio technique.

\subsection{Estimation of the subsurface structures on the western and eastern part of the flat}

In the previous section, a discontinuity of subsurface structure is inferred along the Hino River. Tsutsui and Kobayashi (1989) attempted a more quantitative evaluation of the discontinuity at the next stage.

They employed a similar scheme as Horike (1985), and estimated the subsurface structure down to the basement rock from observed phase velocities of microseisms 

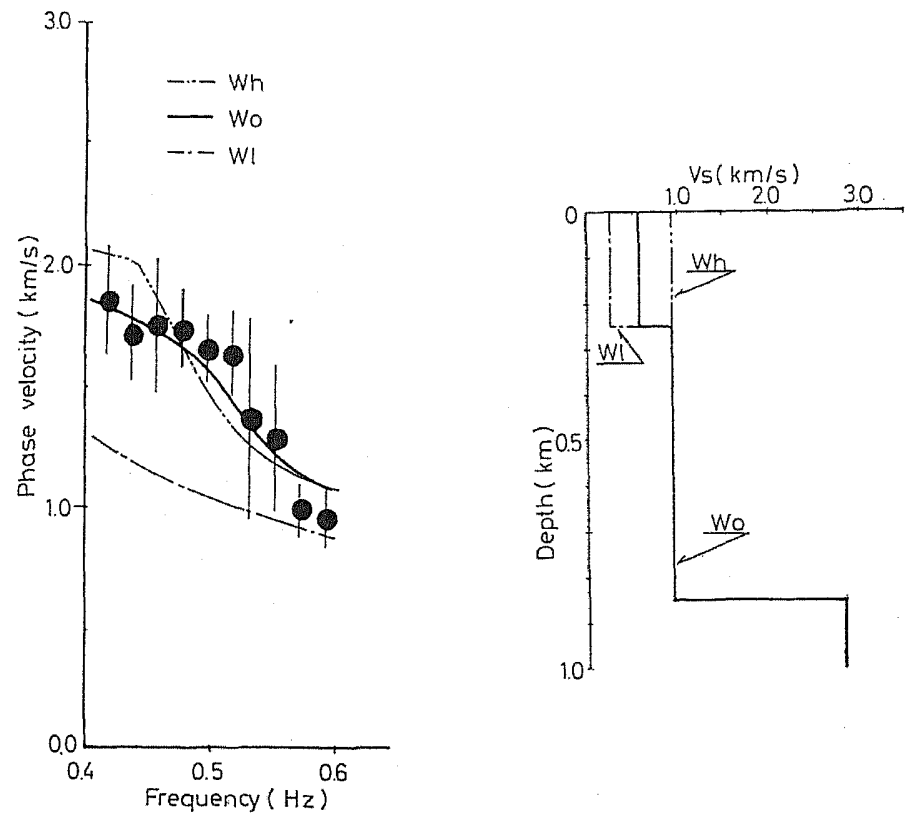

Fig. 5. Calculated and observed phase velocities and corresponding models for WEST-arrays. Solid circles indicate measured phase velocities. The solid line indicates the theoretical dispersion curve for the optimum model Wo. Two variation models, Wh and Wl, are displayed with different dashed lines in the $\mathrm{S}$-wave structure diagram with corresponding theoretical dispersion curves in the left panel. All the theoretical dispersions of the variation models do not fit the observed phase velocity.

across a few two-dimensional arrays. Two array sites are placed on the western and eastern sides of the Hino River flat as shown in Fig. 3 with the largest open circles. The WEST-arrays have two configurations with apertures of 0.5 and $1.0 \mathrm{~km}$, each of which employs five vertical-motion seismometers, while the EAST-array has an aperture of $0.5 \mathrm{~km}$ also with five seismometers.

Phase velocities were estimated through the frequency-wavenumber (f-k) spectra method with high-resolution (Capon, 1969). The results are shown in Fig. 5 for the WEST-arrays and in Fig. 6 for the EAST-array with their variation models. The optimum structure models, Wo and Eo, are refined from those in Tsutsui and Kobayashi (1989). These are constructed on a trial-and-error basis by fitting the theoretical dispersion curves of the fundamental mode Rayleigh waves to the observed values. Some constraints and assumptions are introduced for constructing the structure models. In the WEST-arrays, the depth of the basement rock is fixed at about $0.8 \mathrm{~km}$, referring to the deep-drilling $\log$ (Yokoyama et al., 1976) at $2 \mathrm{~km}$ west of the arrays, and the optimum S-wave velocities in the unconsolidated sediments above the basement are evaluated. In the EAST-array, the depth of the basement rock is sought under the assumption that the $\mathrm{S}$-wave velocities in Kobiwako- and Biwako-group sediments are similar to those in

Vol. 38, No. 6,1990 


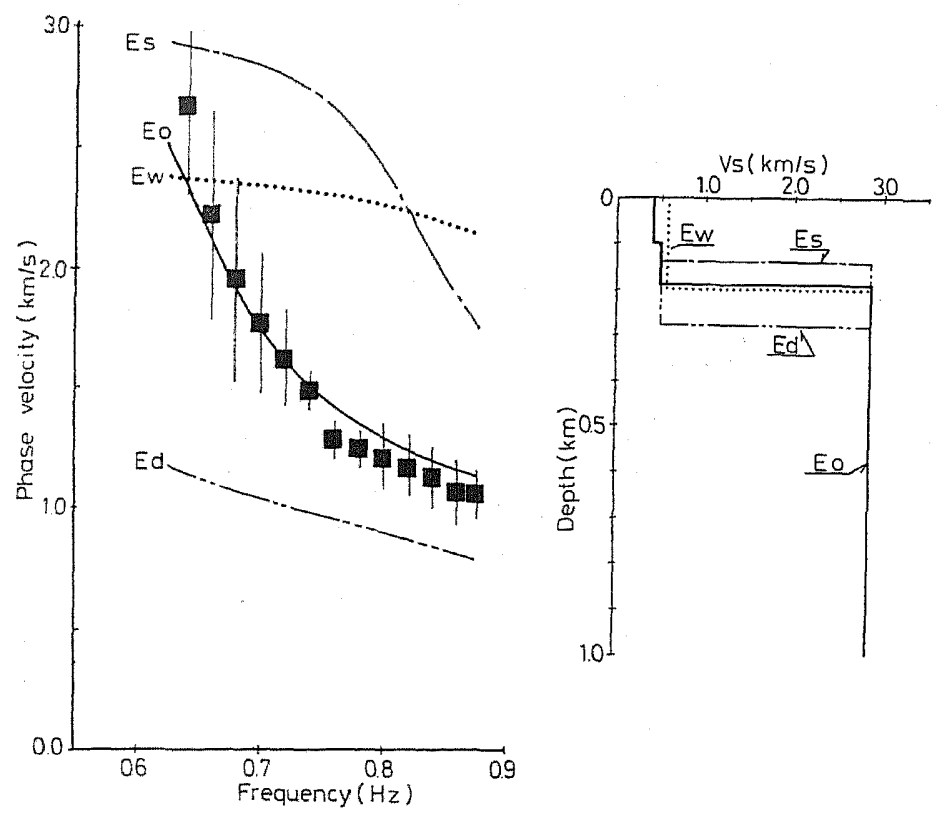

Fig. 6. Calculated and observed phase velocities for various models for EAST-array. Solid squares indicate measured phase velocities. The solid line indicates the theoretical dispersion curves for the optimum model Eo. Several variation models Ew, Ed, and Es are displayed with different dashed lines in the S-wave structure diagram with corresponding theoretical dispersion curves in the left panel. All the theoretical dispersions of the variation models do not fit the observed phase velocity.

the WEST-arrays.

The structure models $\mathrm{Wh}$ and $\mathrm{Wl}$ are variations of model Wo with varied S-wave velocity in the first layer by keeping Poisson's ratio constant, as shown in Fig. 5. Neither of these variational models can explain the observed phase velocities of microseisms. Likewise, models Ew, Es, and Ed which assume different basement depths to model Eo do not support the observations at all. Thus models Wo and Eo are considered to be optimum. Model parameters of Wo and Eo are listed in Table 1(a) and (b), respectively. It is suggested that the depth of the basement rock in the western part of the Hino River flat is greater by $0.6 \mathrm{~km}$ than that in the eastern part.

\section{Reflection Surveys}

\subsection{Velocity structures around the Hino River}

Tsutsui et al. (1989) carried through a CDP method (reflection survey) in order to investigate more detailed structure and to detect the discontinuity of subsurface structure which had been inferred through the previous surveys. Two reflection lines were designed: Line 88-12 to the east and Line 87-10 to the west of the Hino River. 
Table 1, The optimum subsurface structure models estimated from microseisms.

(a) The model Wo for the WEST-arrays

\begin{tabular}{cccc}
\hline$V_{\mathrm{P}}(\mathrm{km} / \mathrm{s})$ & $V_{\mathrm{S}}(\mathrm{km} / \mathrm{s})$ & Density $\left(\mathrm{g} / \mathrm{cm}^{3}\right)$ & Thickness $(\mathrm{km})$ \\
\hline 1.80 & 0.65 & 1.90 & 0.25 \\
2.10 & 0.95 & 2.20 & 0.60 \\
5.50 & 2.70 & 2.50 &
\end{tabular}

(b) The model Eo for EAST-array

\begin{tabular}{cccc}
\hline$V_{\mathrm{P}}(\mathrm{km} / \mathrm{s})$ & $V_{\mathrm{S}}(\mathrm{km} / \mathrm{s})$ & Density $\left(\mathrm{g} / \mathrm{cm}^{3}\right)$ & Thickness $(\mathrm{km})$ \\
\hline 1.60 & 0.40 & 1.90 & 0.10 \\
2.00 & 0.50 & 2.20 & 0.09 \\
5.50 & 2.70 & 2.50 & \\
\hline
\end{tabular}
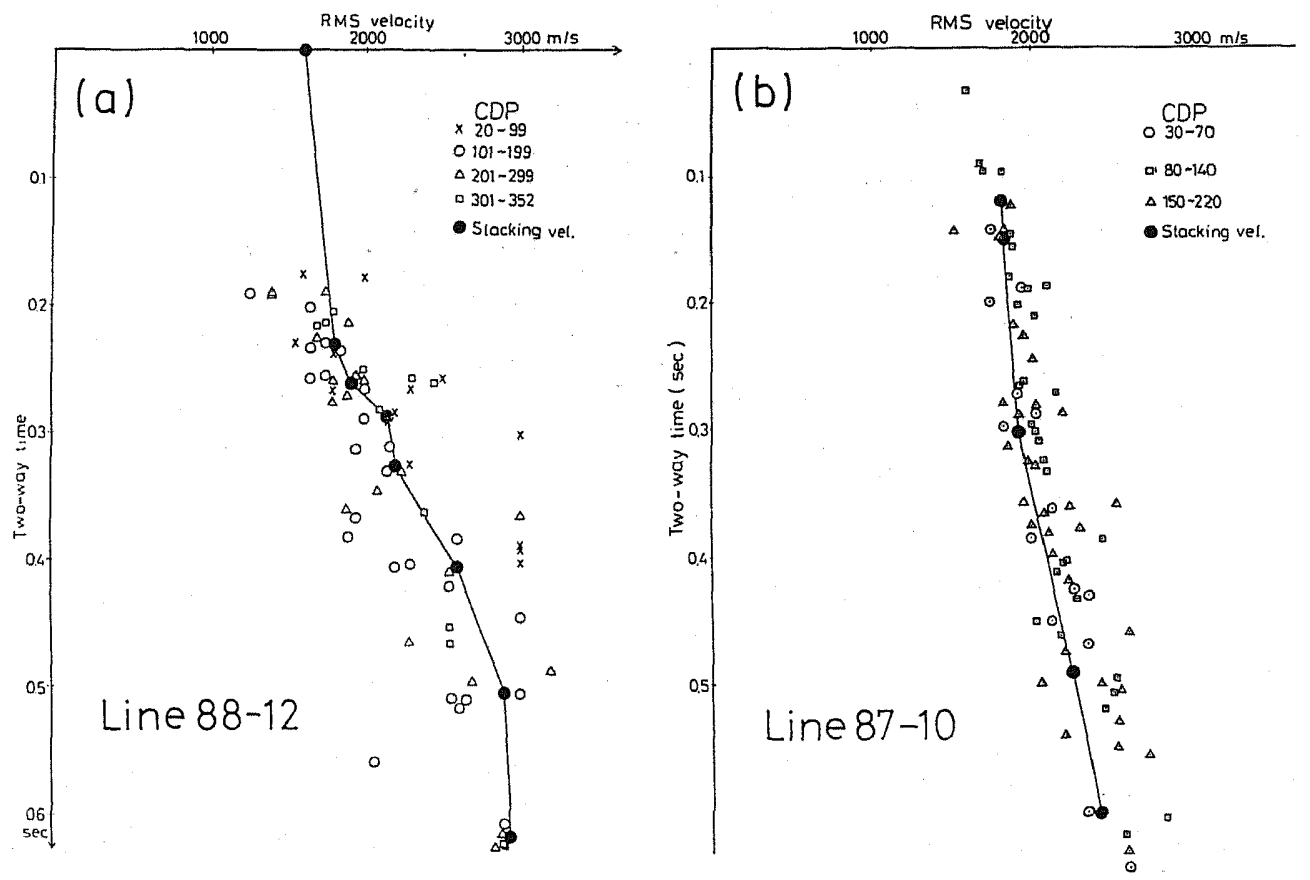

Fig. 7. Estimated RMS velocity (open symbols) and stacking velocity functions (solid lines). (a) for Line 88-12 and (b) for Line 87-10.

The result of the velocity analysis at the CDPs of Line 88-12 and Line 87-10 are displayed in Fig. 7(a) and (b), respectively. The same Root Mean Square (RMS) velocities between 1,700 and $2,000 \mathrm{~m} / \mathrm{s}$ are observed in both lines down to $0.3 \mathrm{~s}$. However, higher velocities tend to appear in Line $88-12$ below $0.3 \mathrm{~s}$. This implies that the basement is shallower under Line 88-12 than under Line 87-10 on the average. Averaged velocity

Vol. 38 , No. 6, 1990 

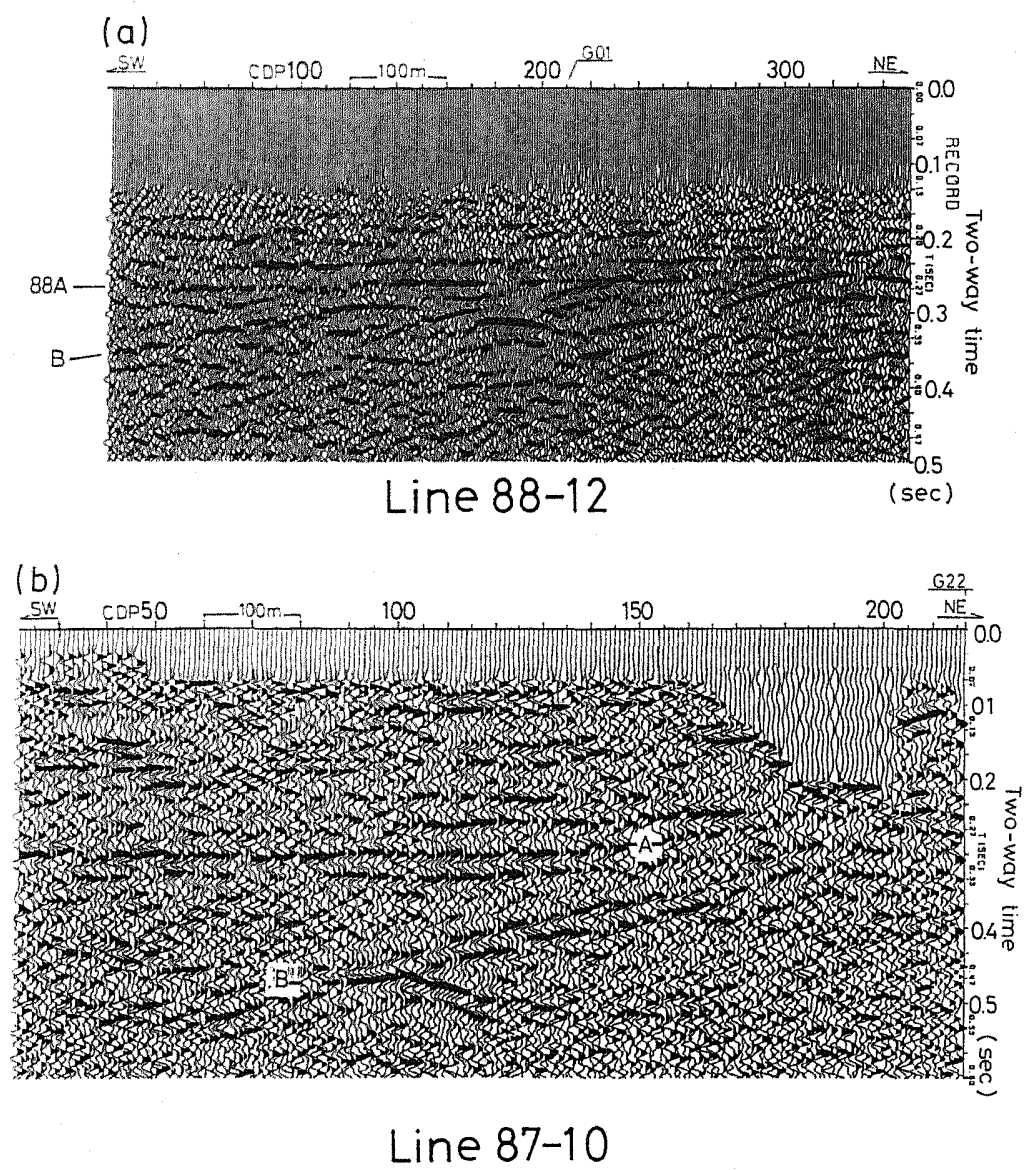

Fig. 8. Filtered stack sections; (a) for Line 88-12, (b) for Line 87-10.

function is adopted for the following CDP stacking of each line, as indicated by the solid lines in Fig. 7.

\subsection{Filtered stack sections}

The filtered stack section of Line 88-12 is shown in Fig. 8(a). The CDP numbers on the abscissa indicate relative locations along the line, and the CDP number increases north-eastwardly. The ordinate is the vertical two-way time in seconds.

Coherent reflections appear horizontally around CDP30 at $0.3 \mathrm{~s}$ of the two-way time and overlap the reflector which has a south-westward dip around CDP240 in Fig. $8(a)$. RMS velocities to these reflections are in the range of 1,900 to $2,000 \mathrm{~m} / \mathrm{s}$. These reflections will be called horizon $88 \mathrm{~A}$, hereafter.

Similar reflections such as horizon $88 \mathrm{~A}$ also appear in the time section of Line 87-10 (Fig. 8(b)) at $0.3 \mathrm{~s}$. The same RMS velocities as for horizon $88 \mathrm{~A}$ are found around these reflections in Fig. 7(b). These reflections will be called horizon $A$, hereafter. 
Coherent dipping reflections beneath horizon $\mathrm{A}$ appear around $0.37 \mathrm{~s}$ at CDP50 and around $0.27 \mathrm{~s}$ at CDP350 in Line 88-12. No coherent reflection is observed below these reflections. These reflections have an RMS velocity of $1,800 \mathrm{~m} / \mathrm{s}$ around CDP50 and $2,000 \mathrm{~m} / \mathrm{s}$ around CDP350. Similar reflections are also found in Line $87-10$. They appear at $0.5 \mathrm{~s}$ with bowed diffraction around CDP85 and become shallower with increasing CDP number, and they terminate around $0.4 \mathrm{~s}$ at CDP165. Since the same characteristics are found in these reflections in Line 88-12 and Line 87-10, they are considered to correspond to the same horizon. These reflections will be called horizon $B$, hereafter.

\subsection{Migrated sections}

The depths are estimated at 300 to $280 \mathrm{~m}$ for horizon $\mathrm{A}$ and at $270 \mathrm{~m}$ for horizon $88 \mathrm{~A}$ by assuming that the depth equals the product of a half of the vertical two-way time and RMS velocity to the reflector.

With regard to horizon $B$, the shape of this horizon can be mis-interpreted because of masking by some diffraction patterns within; the filtered stack sections are processed with the two-dimensional f-k migration scheme of Stolt (1978). The results are displayed in Fig. 9(a) for Line 88-12 and (c) for Line 87-10 with their interpretations in Fig. 9(b) and (d), respectively. The depth to horizon B in Line $88-12$ is estimated as $350 \mathrm{~m}$ around CDP80 and $310 \mathrm{~m}$ around CDP240. Figure 9(c) is greatly improved. The 'bow tie' diffraction around CDP85 has been migrated completely and the concave form of horizon B is clearly identified after migration. The depth to horizon B along Line 87-10 is estimated at about $510 \mathrm{~m}$ at CDP90, $490 \mathrm{~m}$ at CDP70, $440 \mathrm{~m}$ at CDP57. This horizon disappears farther southwest than CDP57.

Tsutsui et al. (1989) concluded that horizon B is an unconformity between Kobiwako-group sediments and the basement rock; its average depth along the lines is on the order coincident with that of gravity survey. And the general trend is consistent with basement rock outcrops to the northeast in the neighborhood of the site.

\section{Pseudo-Reflection Profiling}

\subsection{Seismic time tie between two separated reflection lines}

The ARRAY 89 (G1-G22, R4 and R41) is deployed between the two reflection lines (Fig. 3) and the "Tokuyama-Kamigohri Explosion, 1989" by the Research Group for Explosion Seismology is observed with this array. The seismograms are processed into the Pseudo-Reflection profiles with the method described in Appendix: The details of the method are referred to Tsutsui (1990).

The final Pseudo-Reflection profile, which is a stack of the profiles for the shot points S1 and S2 and then processed with predictive deconvolution (Robinson, 1957), is displayed in Fig. 10 together with the layout of the stations G1-G22. The seismograms at the station R5 were used as the equivalent incident wavelet. Several reflection phases appear coherently in the lateral direction in this profile; phases $\# 1$ at $0.3 \mathrm{~s}$ and $\# 2$ at $0.33 \mathrm{~s}$ around $\mathrm{G} 1$, and phases \#3 at $0.2 \mathrm{~s}, \# 4$ at $0.3 \mathrm{~s}$ and $\# 5$ at $0.34 \mathrm{~s}$ around G22. These phases \#1-\#5 will be called the horizons \#1-\#5, hereafter. Horizon \#4 inclines gently and finally overlaps horizon \#5 at G15. It is of interest that horizon \#2 appears to dip 


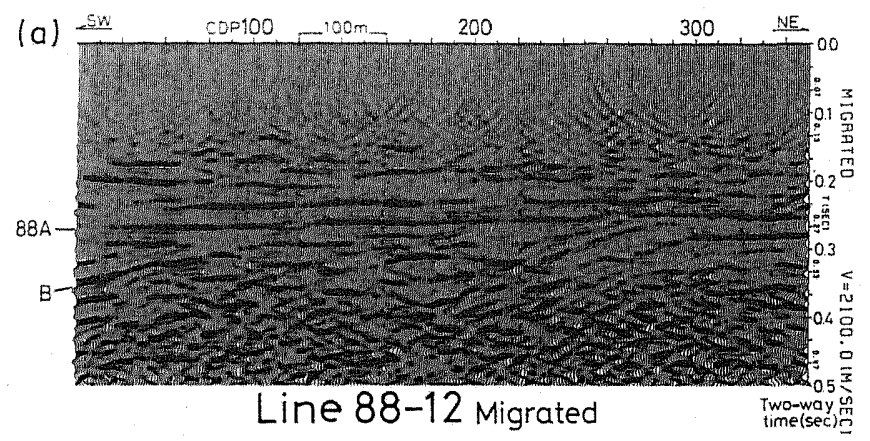

(b)
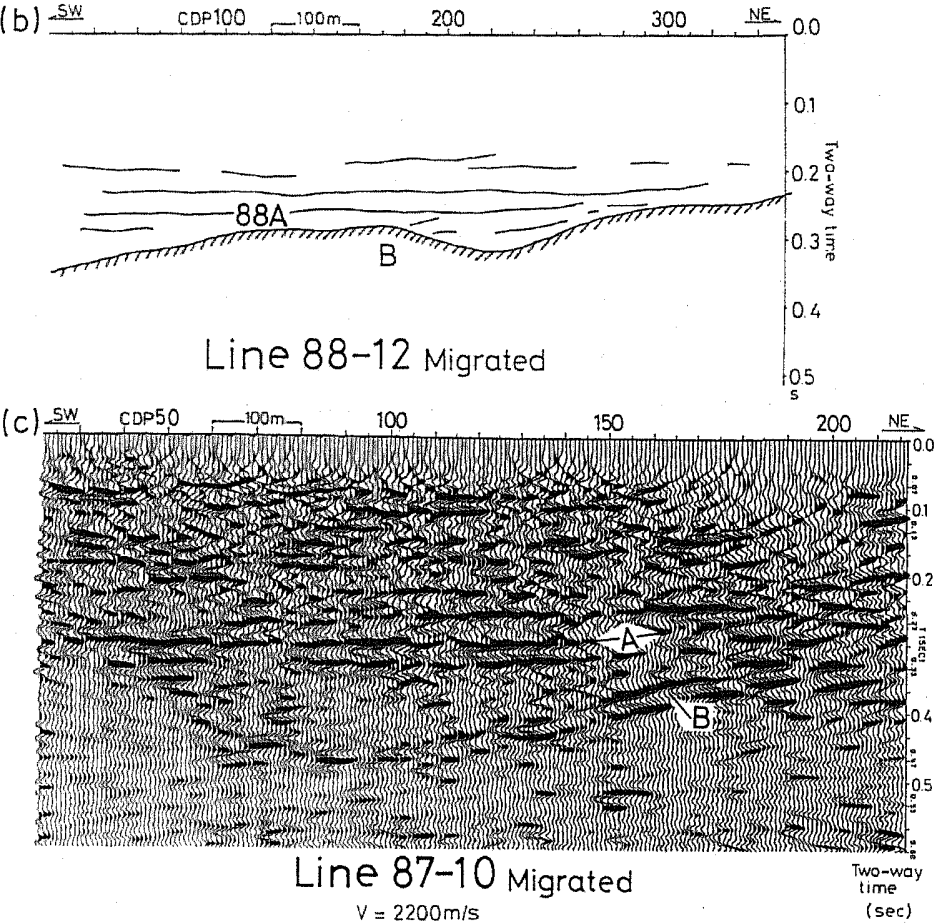

(d)

$v=2200 \mathrm{~m} / \mathrm{s}$

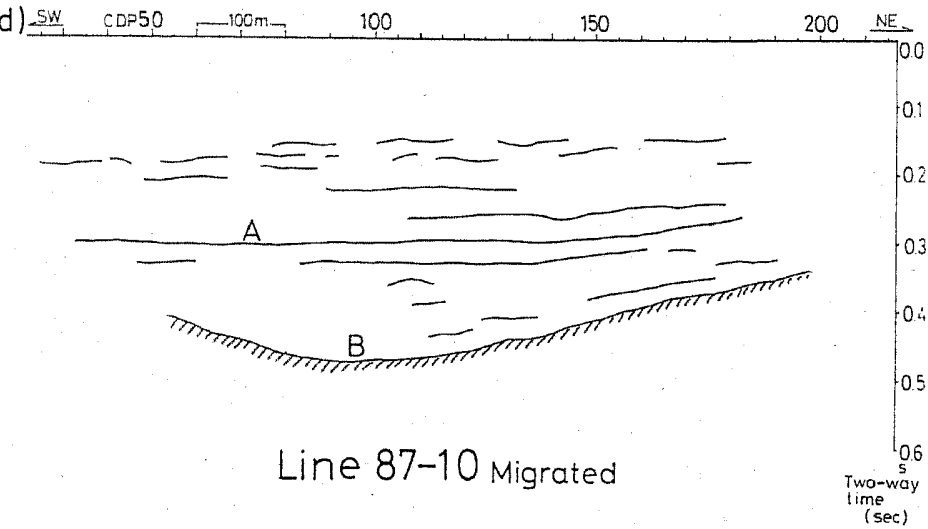

Fig. 9

J. Phys. Earth 


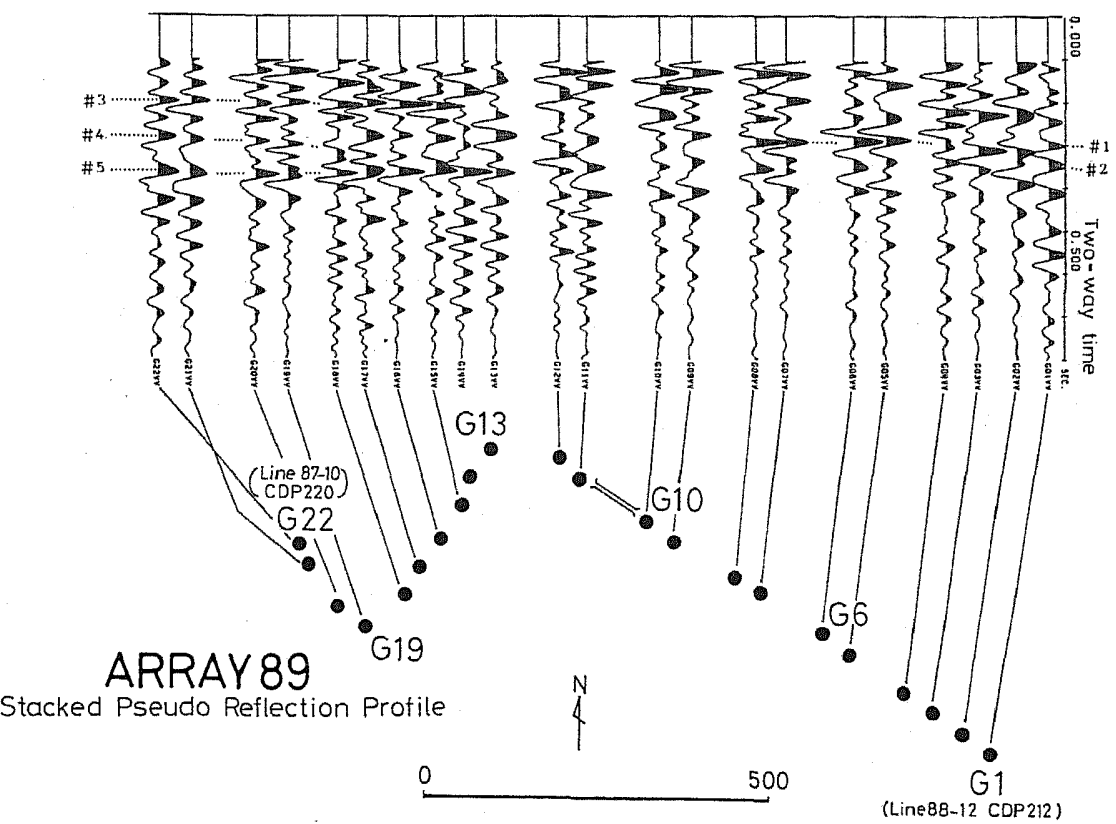

Fig. 10. Stacked Pseudo-Reflection profiles with predictive deconvolution. The prediction distance is $35 \mathrm{~ms}$ and the operator length is $71 \mathrm{~ms}$ for the predictive deconvolution. All traces are muted for $106 \mathrm{~ms}$ in the beginning. The numbers $\# 1-\# 5$ are phase indices.

steeply toward the east end of the profile. A discontinuity in the profile appears around G10. Horizons \#3 and \#5, which align almost horizontally, are traceable until G10 and become ambiguous beyond this station.

The seismic time tie between the reflection profiles (Tsutsui et al., 1989) and the Pseudo-Reflection profile are shown in Fig. 11, in order to correlate the horizons in the two reflection profiles with those in the Pseudo-Reflection profile. The horizons except for \#3 in the Pseudo-Reflection profile have corresponding horizons in the reflection profiles. Horizons \#1 and \#2 are correlated with horizons 88A and B in the profile of Line 88-12, respectively. Horizons \#4 and \#5 correspond to horizons A and B in Line 87-10, respectively. Horizon \#5 can possibly be associated with horizon \#2 which becomes clear toward G1.

Another seismic time tie is shown in Fig. 12. This is a tie between the independent stations R4/R41 and the profile of G1-G22 in ARRAY 89. There are three prominent reflection phases at $0.2 \mathrm{~s}, 0.3 \mathrm{~s}$ and around $0.4-0.5 \mathrm{~s}$ in this tie. The first at $0.2 \mathrm{~s}$ and the second at $0.3 \mathrm{~s}$ correspond to horizons $\mathrm{C}$ and $\mathrm{A}$ in the profiles of $\mathrm{G} 1-\mathrm{G} 22$, respectively. The phases at $0.4-0.5 \mathrm{~s}$ have a striking feature similar to those for horizon B where small onset. is succeeded by greater swings, so that these may correspond to horizon B

Fig. 9. Migrated sections with their interpretations. (a) Line $88-12$ and (b) its interpretation. (c) Line 87-10 and (d) its interpretation.

Vol. 38 , No. 6, 1990 


\section{The Seismic Tie}

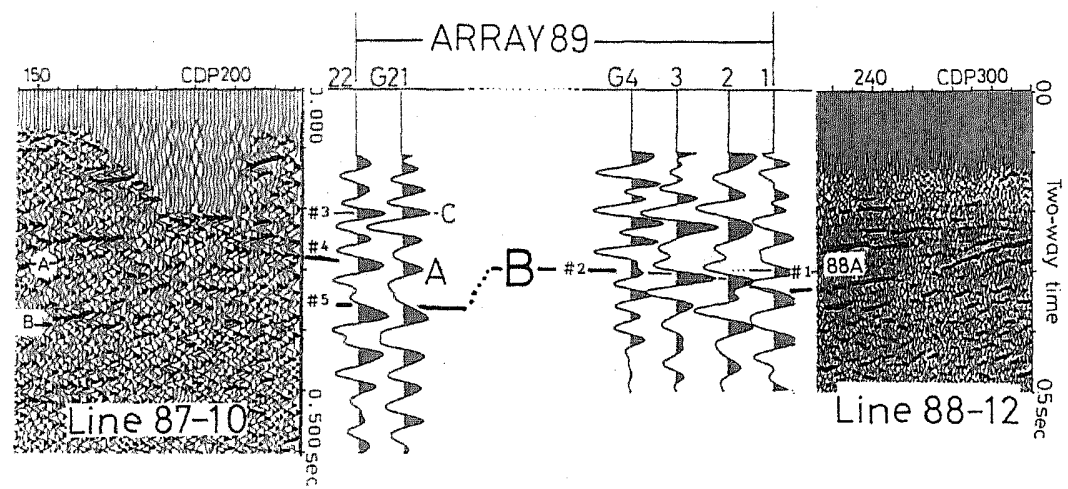

Fig. 11. Seismic time tie between ARRAY 89 and the two reflection lines. They show good correlations of the horizons at each ends of ARRAY 89 with the reflection profiles.

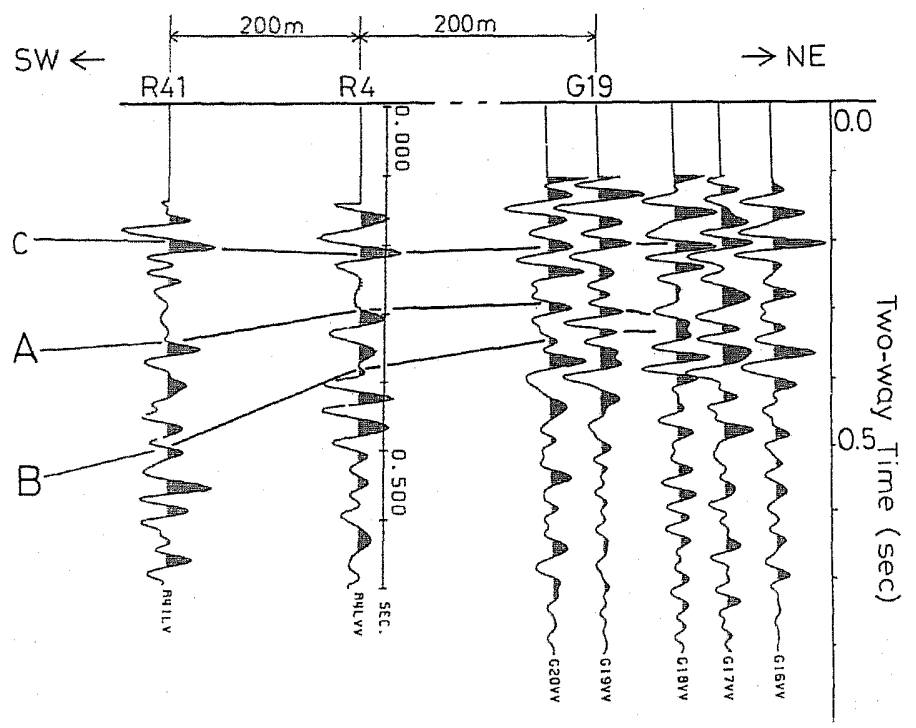

Fig. 12. Seismic time tie between R4, R41, and ARRAY 89. The B plane shows a dip similar to that in the profile of Line 87-10.

in the profile of G1-G22. Horizon B in this tie has an apparent south-westward dip. This tendency of the horizon is similar to that of the corresponding horizon in the profile of Line 87-10, parallel to R4-R41 as shown in Fig. 13. Horizons A and C at R4 and R41 also have a similar dip but have greater depth than those in the reflection profile of Line 87-10.

Therefore, a buried valley detected across Line 87-10 lies certainly close under the 

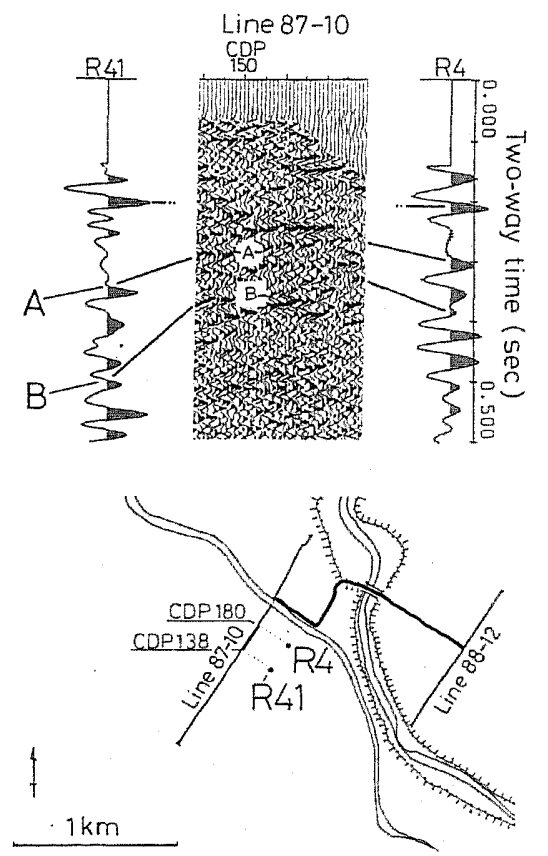

Fig. 13. Comparison of $\mathrm{R} 4 / \mathrm{R} 41$ and the Line 87-10 time section. The horizon $\mathrm{A}$ and $\mathrm{B}$ at R4 and R41 are appreciably deeper than those in the profile of Line 87-10.

south of ARRAY 89. There must be some variation in its cross section since the dip of horizon $\mathrm{B}$ differs depending on the place.

\subsection{Correlation of reflection profiles with the deep-drilling log}

The correlation of profiles around the Hino River with the deep-drilling log obtained on the estuary of the Yasu River was investigated by using the Pseudo-Reflection Profiling along the refraction line R1-R4.

Open triangles in Fig. 3 show locations of the stations R1-R4 on the refraction line. The average interval of the stations was about $2 \mathrm{~km}$. Station R1 was located $700 \mathrm{~m}$ SSE of the deep drilling site, and R2, $600 \mathrm{~m}$ north of the WEST-arrays. R3 is on the identical place with the OBS-g of Tsutsui and Kobayashi (1989). The source data for the profiling are seismograms of the "Tokuyama-Kamigohri Explosion, 1989." The seismograms at station R5 were again used as the equivalent incident wavelet for the data processing. All processing procedures are the same as those in the previous Sec. 4.1 (see also Appendix).

Figure 14(a) shows the final Pseudo-Reflection profile along the refraction line, which includes the traces of R4 and R41. Figure 14(b) shows the Bouguer anomaly distribution along this line.

At first, the correlation of the Pseudo-Reflection trace at R1 with the deep-drilling $\log$ at $700 \mathrm{~m} \mathrm{NNW}$ of R1 is examined. Figure 15 shows both the data and the result of

Vol. 38; No. 6, 1990 


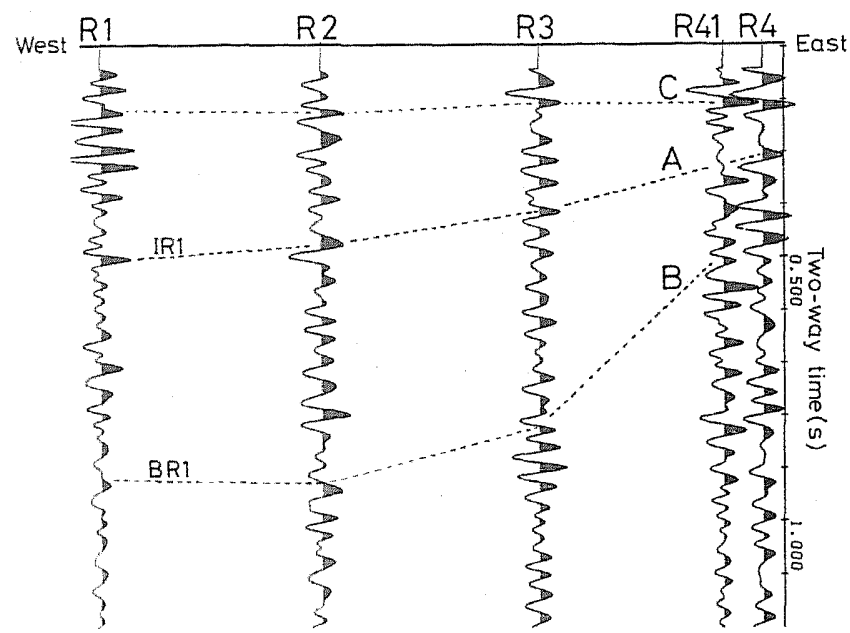

(a)

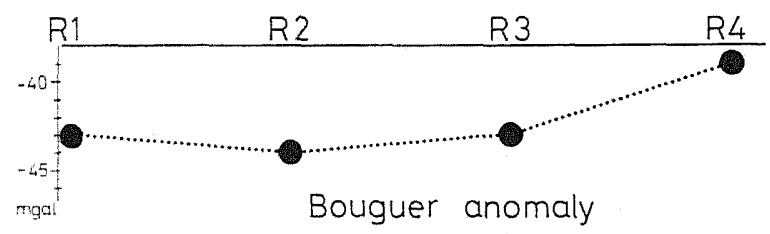

(b)

Fig. 14. Pseudo-Reflection profile (a) and the Bouguer anomaly profile (b) after Nishimura (1979) across the Hino River flat.

interpretation which is shown with broken lines. In order to interpret the reflection phases of R1, a model is constructed from the description on consolidation of drilling-core samples in Yokoyama et al. (1976) and the velocity data in Sugimoto (1977) and Ikawa (1988). The model parameters are listed in Table 2. The vertical two-way travel times of expected reflection phases for this model are calculated for correlating the depths of reflectors and interfaces in the drilling log.

The reflection phase FR1 at $0.3 \mathrm{~s}$, which has the largest amplitude in the Pseudo-Reflection trace of R1, corresponds to the bottom of bed F (depth: $267 \mathrm{~m}$ ) in the drilling log. This correspondence is probable because a large reflection is expected in the bottom of bed $\mathrm{F}$ where a significant change in the consolidation is reported (Yokoyama et al., 1979). Correspondence of the other phases to interfaces in the drilling $\log$ is as follows: DR1 at $0.25 \mathrm{~s}$ to the bottom of bed D $(200 \mathrm{~m}), \mathrm{HR} 1$ at $0.38 \mathrm{~s}$ to the bottom of bed $\mathrm{H}(326 \mathrm{~m})$, the impulsive phase IR1 at $0.5 \mathrm{~s}$ to the bottom of bed I $(500 \mathrm{~m}), \mathrm{JR} 1$ at $0.70 \mathrm{~s}$ to the bottom of bed J $(652 \mathrm{~m}), \mathrm{KR} 1$ at $0.75 \mathrm{~s}$ to the bottom of bed $\mathrm{K}(717 \mathrm{~m})$ and LR1 at $0.84 \mathrm{~s}$ to the bottom of bed L $(806 \mathrm{~m})$.

The phase BR1 at $0.91 \mathrm{~s}$ seems to be the reflection from the top of the basement below the bottom of the deep drilling. The depth of the reflection plane for BR1 is 


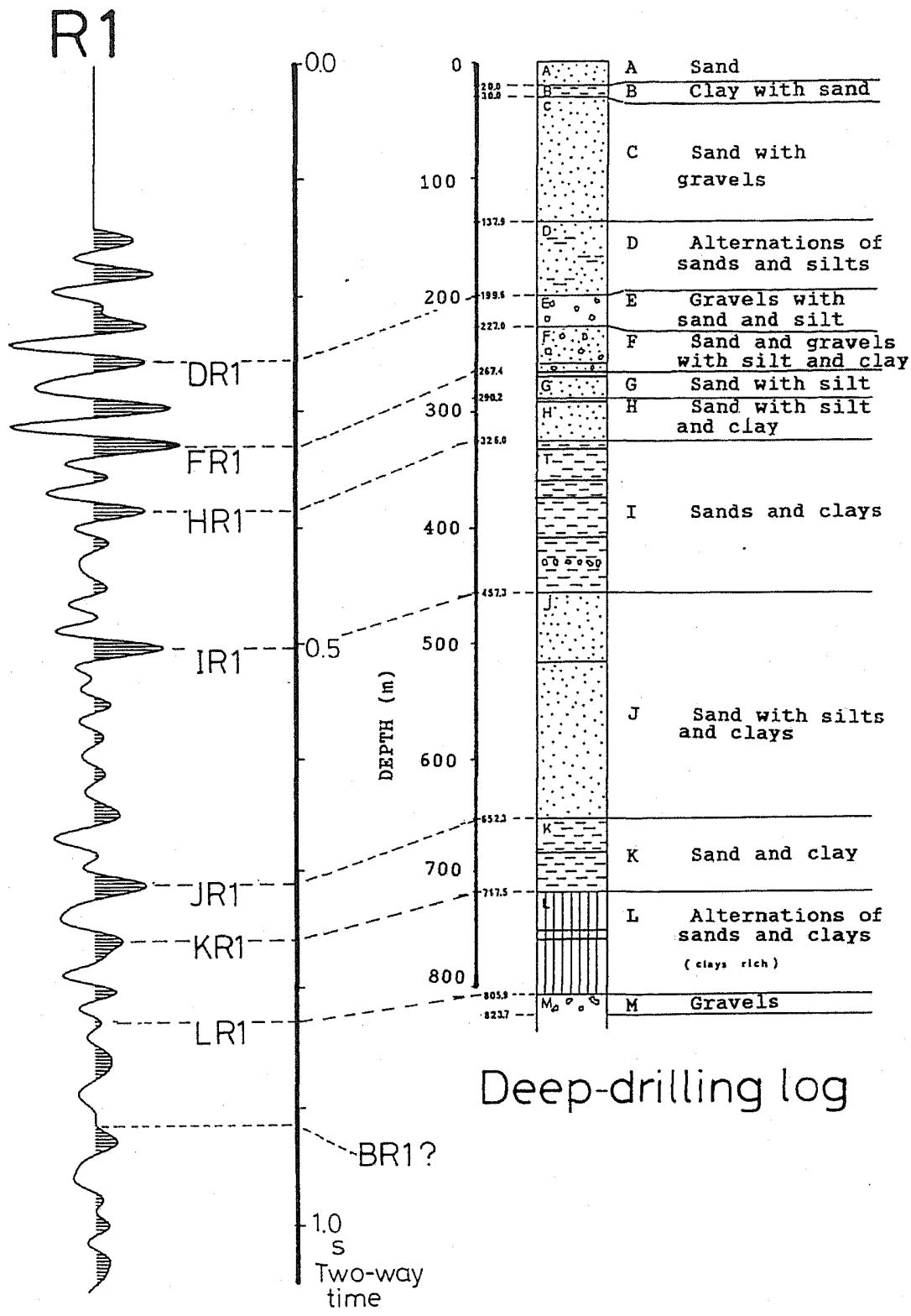

Fig. 15. Comparison between the deep-drilling log and the Pseudo-Reflection seismogram at station R1.

estimated to be about $920 \mathrm{~m}$ because the thickness of the basal conglomerate should not be far different from $100 \mathrm{~m}$ referring to the result of another deep-drilling $10 \mathrm{~g}$ in the lake (Yokoyama and Takemura, 1983). Furthermore, this supposition is consistent

Vol. 38 , No. 6,1990 
Table 2. The velocity model for deep-drilling log on the estuary of the Yasu River (Southern branch).

\begin{tabular}{lccc}
\hline Layer & $V_{\mathrm{p}}(\mathrm{m} / \mathrm{s})$ & Bottom depth $(\mathrm{m})$ & Two-way travel time $(\mathrm{s})$ \\
\hline AD & 1,600 & 200 & 0.250 \\
E & 1.800 & 227 & 0.280 \\
F & 1,700 & 267 & 0.322 \\
GH & 2,000 & 326 & 0.382 \\
I & 2,100 & 457 & 0.510 \\
J & 2,200 & 652 & 0.688 \\
K & 2,300 & 718 & 0.745 \\
L & 2,400 & 806 & 0.818 \\
M & 2,450 & $>900$ & Around $0.895 ?$ \\
B & 3,000 & - & - \\
\hline
\end{tabular}

with model Wo.

Next, correlation of the reflection phases through the rest of the stations is discussed. These stations have no direct information about stratification as in the case of R1. Therefore, the following assumptions are invoked: there is little variation in the average $\mathrm{P}$-wave velocities and there is no change of stratification in Kobiwako-and Biwako-group deposits beneath this survey line.

The prominent and impulsive phases which appear in the range of 0.3 to $0.5 \mathrm{~s}$ at R2 and R3 are correlated to the reflection IR1 at R1 through their waveforms which have an isolated phase preceded by a quiescence for about $0.05 \mathrm{~s}$. Horizon A at R4 and $\mathrm{R} 41$ is also correlated to this phase. Another kind of prominent phases with large amplitudes between 0.8 and $1.0 \mathrm{~s}$ is considered to be the reflections from the top of the basement which has a high impedance contrast to the layers above. They are correlated to phase BR1 at R1 and the horizon B at R4 and R41. Later phases at R4 and R41 may be ghost phases caused by some kind of contamination, e.g., P-SV converted waves, because horizon B has no coherent reflection below it (Tsutsui et al., 1989). All these interpretations are displayed in Fig. 14(a) with broken lines.

\section{Discussion}

The topography of horizon B is discussed first. Phase BR1 at R1 seems to be the reflection at the top of the basement as described in Sec. 4.2. Furthermore, it is reasonable to correlate the prominent phase at $0.91 \mathrm{~s}$ at R2 to BR1 because model Wo implies that the top of the basement lies at the depth of about $850 \mathrm{~m}$ at R2 (Fig. 5), and the travel time for this depth agrees reasonably well with that of the prominent phase. A similar phase as BR1 appears also at R3, which is also considered as the reflection at the basement. This consideration is supported by the result of gravity survey by Nishimura (1979) which is shown in Fig. 14(b). A negative Bouguer anomaly shows a similar pattern with that of these phases in the profile in Fig. 14(a). The negative anomaly at $\mathrm{R} 2$ is greater than those at R1 and R3, and seems to be inconsistent with BR1 phase in Fig. 14(a). However, this discrepancy is not grave because R2 station is not identical 
to the gravity station of Nishimura (1979), while the positions of R1 and R3 are identical in both studies. Consequently, no considerable difference in the depth of the basement exists between R1 and R3. The depth of the basement is estimated to be about $800 \mathrm{~m}$ at R3. Since the basement depth is estimated at about $400 \mathrm{~m}$ at Hino River site (R4, R41, ARRAY 89 and two reflection lines) and at about $800 \mathrm{~m}$ at R3, a steeply tilted basement is inferred between R3 and the Hino River site.

Tsutsui and Kobayashi (1989) measured microseisms on almost the same observation lines. The frequency components in the range lower than $0.5 \mathrm{~Hz}$ become larger to the west than those to the east of the Hino River. And the peak frequencies of the spectral ratio in Fig. 4(a) and (b) on these lines become lower westwardly. A similar phenomenon was described by Kasuga (1983) and this is considered as an effect of the change in the thickness of unconsolidated sediment. Hence, these results of the spectral ratio of microseisms give another evidence for westwardly increasing depth of the unconsolidated sediments, Kobiwako- and Biwako-group.

As described above, it is certain that a steep dipping plane of the basement exists in the west of the Hino River. Furthermore, a strike of the dipping plane is important in order to discuss the tectonic significance of the structure. Tsutsui et al. (1989) suggested that there must be a dipping basement with a north-south strike in the northwest of the reflection lines. The f-k spectra (Fig. 16(a) and (b)) of the explosion seismograms from ARRAY 89 given by Tsutsui (1990) support this conjecture. That is, the incident azimuth determined with $\mathrm{f}-\mathrm{k}$ spectra for the shot point $\mathrm{S} 1$ in Fig. 16(a) is coincident with the geometrical azimuth of the shot point in northeast, while the incident azimuth determined likewise for the shot point S2 in Fig. 16(b) is due north and does not agree with the geometrical azimuth in the northwest. The deflection seems to occur only for the incidence from thicker-sediment direction like in the case of S2. A similar phenomenon was described by Irikura and Akamatsu (1974) and Nishimura and Morii (1985). Irikura and Akamatsu (1974) observed a north- or southward deflection of incident waves at a westward-dipping site for events in the west, i.e., the thicker-sediment direction. The deflection trend is the same as shown in Fig. 16(b). Furthermore, the relative scale of the basement depth of $300-500 \mathrm{~m}$ to the wave length of about $140 \mathrm{~m}$ in this case (a frequency of $14 \mathrm{~Hz}$ and a velocity of $2 \mathrm{~km} / \mathrm{s}$ in the sediments is assumed) is similar to that in Nishimura and Morii (1985). In summary, it is inferred that a dipping interface at the depth of $0.5-1.0 \mathrm{~km}$ has affected the azimuths of the incident waves with their wavelength of less than $400 \mathrm{~m}$ in the overlaying medium. Hence, the strike of the steep dipping basement between R3 and the Hino River site is certainly south to north.

To the east of the discontinuity, a buried valley of the basement to the south of the reflection lines around the Hino River has been inferred by Tsutsui et al. (1989). The evidence for this valley is also found in the Pseudo-Reflection profiles. Horizon B looks like to tilt toward the junction of ARRAY 89 and Line $88-12$ in Fig. 11, so that the direction of the maximum dip below this place of horizon $B$ is almost due south. Little refinement of the profile around the CDP212 of Line $88-12$ by means of the 2-D f-k migration was accomplished by Tsutsui et al. (1989), and this must be attributed to a three-dimensional structure or a diagonal survey line to the maximum dip direction (e.g., Gibson et al., 1983). Moreover, a steeper dip toward southwest of horizon B 
(a)

$0.000 \quad 1.000 \quad 2.000 \quad 3.000 \quad 4.000 \quad 5.000 \quad 6.000$

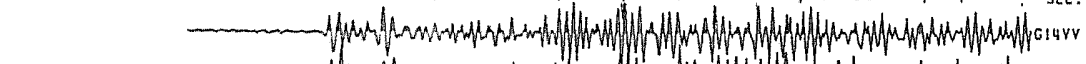

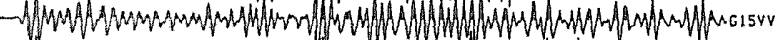

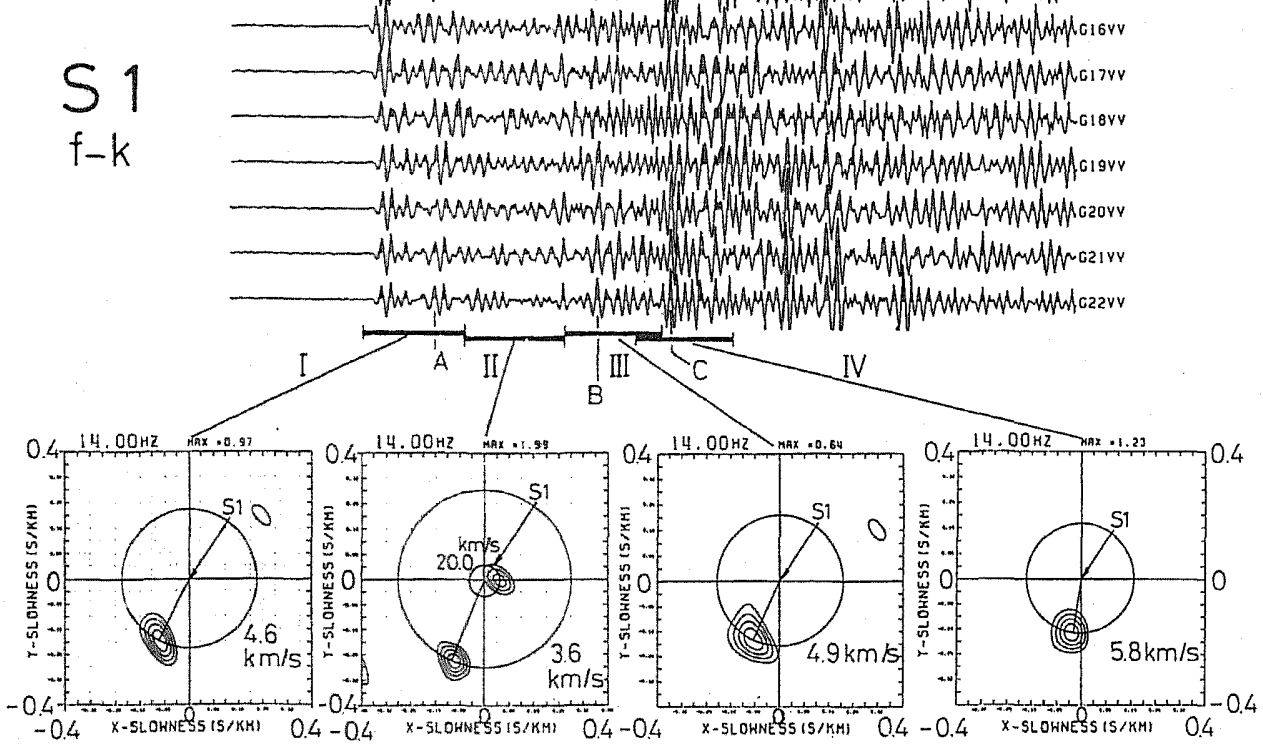

(b)

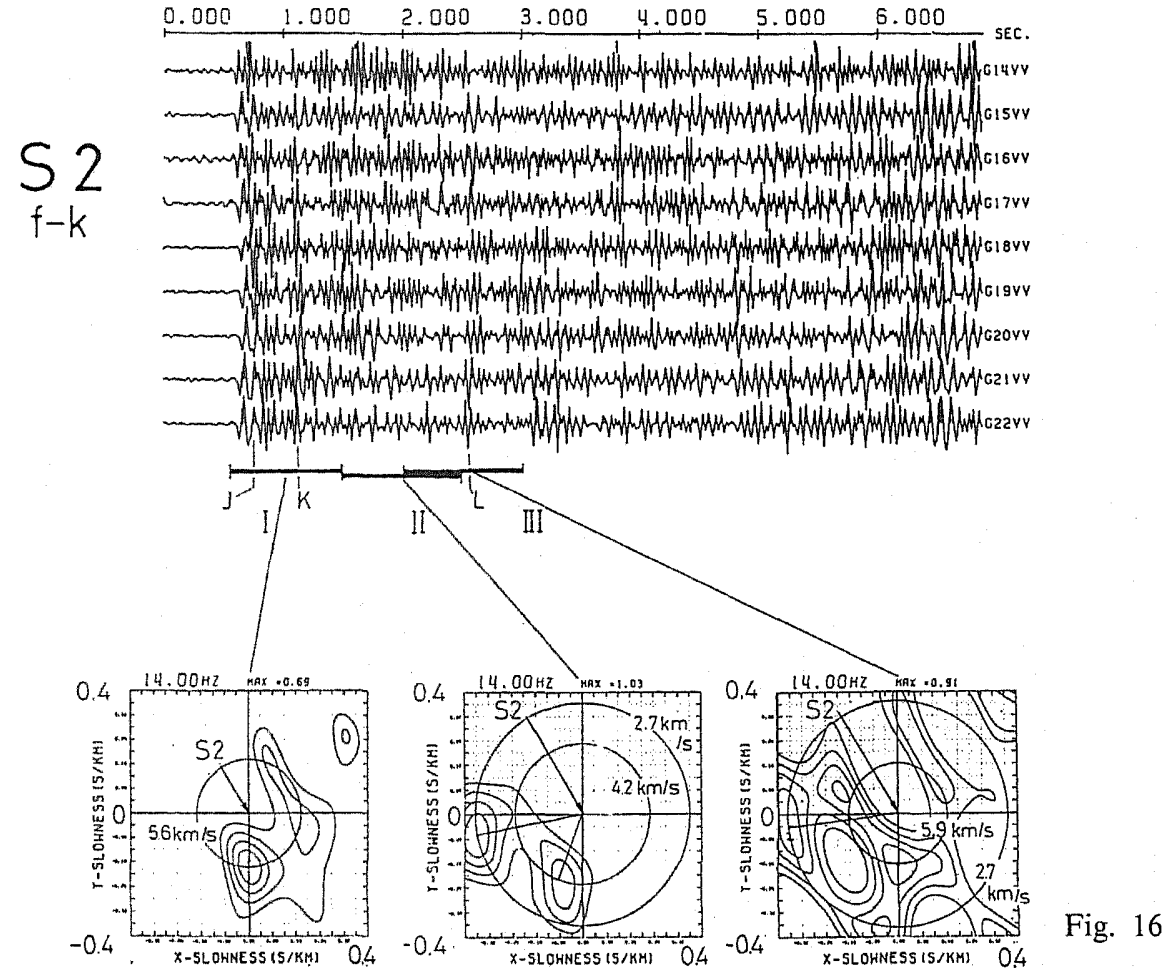

J. Phys. Earth 


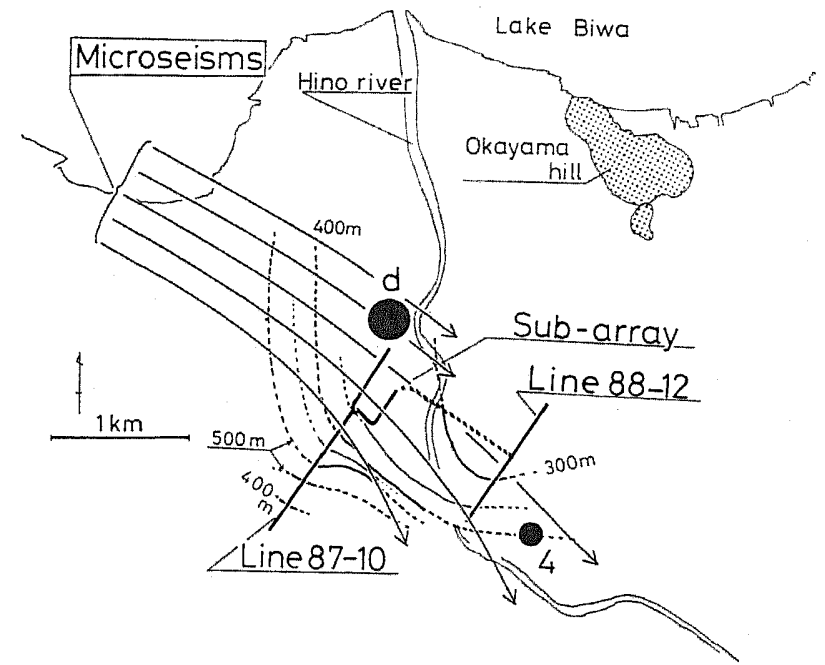

Fig. 17. Subsurface topography and probable propagation of microseisms around OBS-4 and OBS-d through the operation of Line 86-7. Sizes of the symbols at every station are proportional to their spectral ratio in the frequency of around $0.3 \mathrm{~Hz}$, as shown in Fig. 4.

appears in the profile R4/R41 in parallel to Line 87-10 (Figs. 12 and 13). A compilation of depths of horizon B in various profiles shows a buried valley with an ESE-WNW-ward strike on the south of the seismic lines around the Hino River and its cross section is variable place to place. The compiled Bouguer anomaly map by Shichi (1990) also suggests the existence of this buried valley.

The buried valley with its ESE-WNW-ward strike and the dipping basement with its north-south strike can explain the discrepancy between the basement depths and the spectral ratio of the microseisms which was pointed out in Tsutsui et al. (1989), as shown in Fig. 17. The refractions of microseisms can explain the difference of the spectra between OBS-d and OBS-4 qualitatively, if we assume that surface waves, which are predominant in microseisms, impinge slantwise on the westward-dipping basement from the northwest (e.g., Yanovskaya and Roslov, 1989).

A discontinuity of the arrival time for horizon $B$ in the profile of ARRAY 89 appears between G8 and G11 by the Hino River (Fig. 10). This discontinuity of the arrival is equivalent to the discontinuity in the depth of the basement because Fig. 7(a) and (b) show almost the same RMS velocities above this horizon. The discontinuity may imply a hidden fault below the Hino River.

Figure 18 is a compilation of the basement topography around the Hino River flat proposed by this study from the depth map of the horizon B by Horie and Tanaka

Fig. 16. F-k spectra in the sub-array (G14-G22) of ARRAY 89 from Tsutsui (1990), (a) for S1 and (b) for S2. Because of the power spectra with sharp peaks at about $14 \mathrm{~Hz}$, only typical $\mathrm{f}-\mathrm{k}$ spectra at $14 \mathrm{~Hz}$ are displayed with $-1 \mathrm{~dB}$ contour interval. Window positions are indicated below the traces.

Vol. 38 , No. 6,1990 


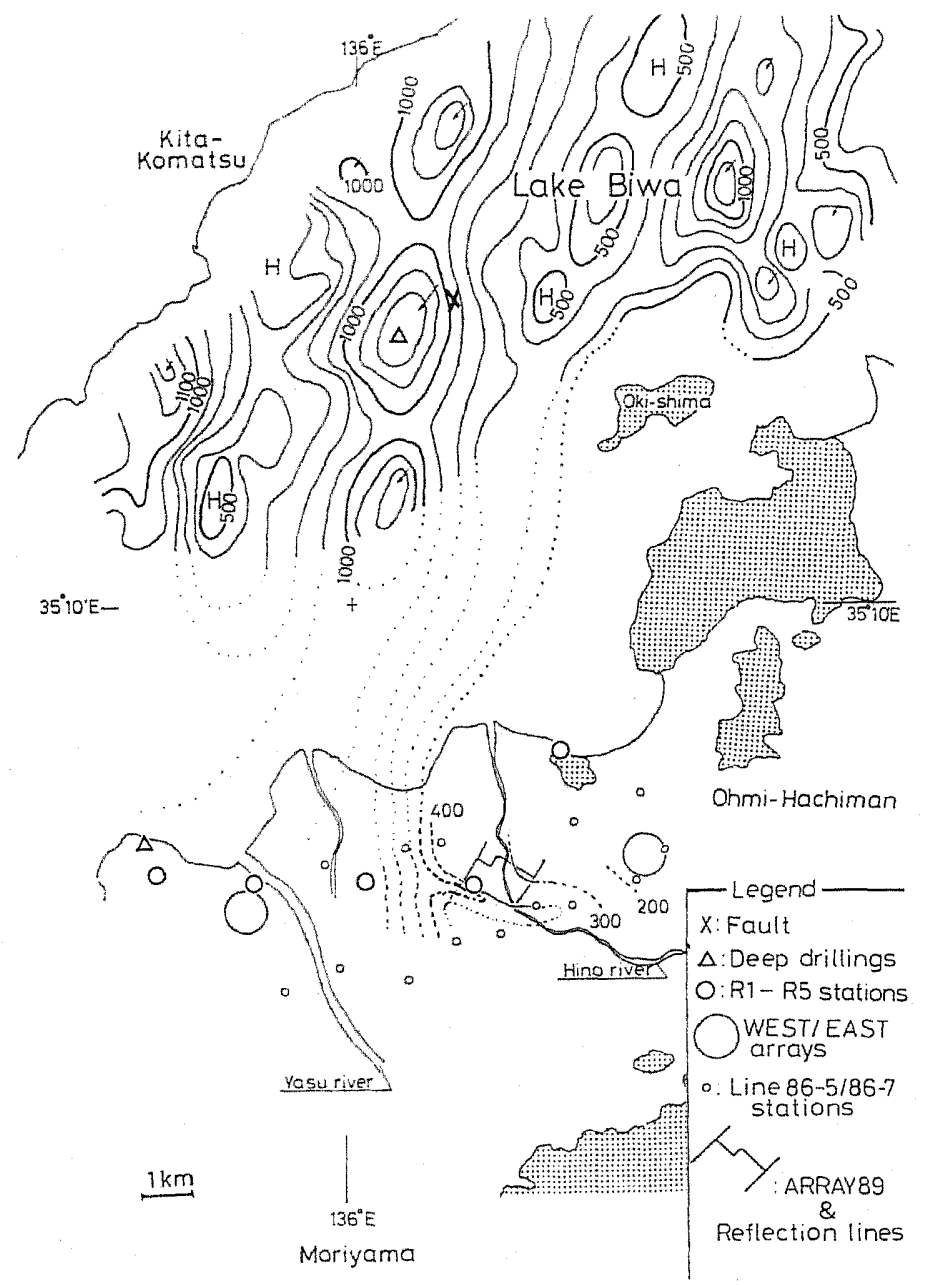

Fig. 18. Subsurface topography of the central basin of Lake Biwa, compiled from the results of this study and those of Horie and Tanaka (1983). Contours indicate the depth of the basement in meter. Screened areas are outcrops of the basement rocks. The triangle in the lake indicates the " $1,400 \mathrm{~m}$ " Deep Drilling Site (Yokoyama and Takemura, 1983), and the other on the shore of the lake is the " $1,000 \mathrm{~m}$ " Deep Drilling site (Yokoyama et al., 1979). " $\mathrm{X}$ " in the center of the lake is the location of the active fault (normal type) which was discovered by Horie and Tanaka (1983).

(1983) beneath the lake. A gradient of $7 \%$ of the basement beneath ARRAY 89 estimated from the difference in apparent velocities for S1 and S2 (Fig. 16) agrees well with the gradient of $8 \%$ obtained at the reflection lines. It is reasonable that horizon B dipping beneath the flat is considered as a part of the southward extension of the valley wall along longitude $136^{\circ} \mathrm{E}$ offshore of the lake. If it were true, this valley with its 
south-northward strike is as long as $10 \mathrm{~km}$ or more. This may be a result of erosion along a fracture zone. Incidentally, Takemura and Yokoyama (1989) reported that fracture of the basement rock was found in the " $1,400 \mathrm{~m}$ " deep drilling (the open triangle in the lake) at the center of the valley $136^{\circ} \mathrm{E}$ in Fig. 18 . Comparing this fact and the seismicity distribution in Fig. 2 again, one can find a considerable change in seismicity across $136^{\circ} \mathrm{E}$. Therefore, the valley $136^{\circ} \mathrm{E}$ is probably a tectonic line bounding the western rim of the seismic-quiescent area south of Lake Biwa.

The depth distributions of horizon A group beneath the Hino River flat is examined last. Horizon $88 \mathrm{~A}$ must be included in horizon $\mathrm{A}$ because of its appearance and its RMS velocity by Tsutsui et al. (1989). Horizon A seems to dip westward in Fig. 14(a) and it is correlated to the top of the bed $\mathrm{J}$ whose age is about 0.47 to $0.87 \mathrm{Ma}$ from core sample analysis by Takemura et al. (1976). And in Fig. 11, horizon A (the phase \#4) which appears at $300 \mathrm{~m}$ in depth beneath a western part of ARRAY 89 dips apparently northward and then overlaps the basement top (the phase \#5) at G15. Therefore, horizon A beneath the flat dips and becomes deeper gradually toward the western shore of Lake Biwa. This dip is consistent with those of the other horizons over the basement rock in a multi-channel profile between the estuary of the Hino River and Kita-Komatsu (Horie and Tanaka, 1983). Horizon A which becomes deeper gradually to north-west and horizon $\mathrm{B}$ which tilts steeply toward $136^{\circ} \mathrm{E}$ may suggest a gap in history of the flat during the Quaternary; a tectonic line along the valley $136^{\circ} \mathrm{E}$ had possibly been active before development of horizon $\mathrm{A}$, and then the tectonic line became inactive and the Hino River flat as a whole as inclined toward northwest in conjunction with the recent development of the Biwako basin.

\section{Conclusion}

1. The basement becomes deeper and the Kobiwako- and Biwako-group sediments become thicker westwardly beneath the Hino River flat. The depth of the basement is $900 \mathrm{~m}$ in the western part and $200 \mathrm{~m}$ in the eastern part of the flat.

2. A hidden dip-slip fault in the basement may exist close to the Hino River.

3. A tectonic line along longitude $136^{\circ} \mathrm{E}$ is inferred. This tectonic line is coincident with the western rim of the seismic-quiescent area in the south of Lake Biwa.

4. Horizon $A$ in the unconsolidated sediments which overlaps the basement around the Hino River dips gently toward the west shore of Lake Biwa. From the difference of topographies of horizons $\mathrm{A}$ and $\mathrm{B}$, it is supported that the tectonic line along $136^{\circ} \mathrm{E}$ had been active until the development of horizon $\mathrm{A}$.

5. A minor buried valley with the ESE-WNW-ward axis exists south of the seismic lines around the Hino River,

I would like to thank Dr. Y. Kobayashi and Dr. K. Irikura for encouragement during their supervision of this work. I would like to thank also Dr. T. Iwata for fruitful discussions. Without the cooperation of the persons listed below, this study would not have been possible: Messrs. S. Abe, E. Fukuyama, T. Kagawa, S. Yoshioka, M. Higashi, M. S. Fukuyama, M. Fujita, Y. Shiba, Y. Suda, T. Fukui, H. Fujiwara, Y. Murai, M. Hiasa, K. Tasaki, M. Hamanaka, I. Minematsu, M. Ohshima, I. Matsui, S. Moriya, Y. Okamoto, H. Tanaka, S. Kawasaki, T. Iguchi,

Vol. 38 , No. 6,1990 
Sri Widiyantoro, Y. Takaoka, H. Nakamura, S. Aoi, S. Sawada, N. Matsuyama, C. Fu.

Japex Geoscience Institute Co. Ltd. permitted us to use Yuatsu-Impacter, and Hanshin Consultants $\mathrm{Co}$. Itd. cooperated in the reflection surveys. I received the kind permission to occupy arable roads for the observations from the Regional Center of Arable Development, West Ohmi-Hachiman city, residents of Ohmi-Hachiman city, Chuzu town and Moriyama city. Dr. $\mathrm{K}$. Ito provided a seismicity map for this study and informed me of the details of "Tokuyama-Kamigohri Explosion, 1989." He and other participants of the Research Program for Active Faults in the Southwest Japan allowed us to use some part of their apparatuses for our specific observations. I received kind suggestion of Dr. K. Nishimura in searching references. Some of the computer programs for analysis of microseisms were coded by Dr. M. Horike.

Data processing was run on FACOM M780 in the Data Processing Center, Kyoto University. This research was supported in part by a Project for Earthquake Prediction in the Kinki-Keihanshin Area, Kyoto University and a Research Program for Active Faults in Southwest Japan.

\section{REFERENCES}

Capon, J., High resolution frequency wavenumber spectral analysis, Proc. IEEE, 57, 1408-1419, 1969.

Claerbout, J. F., Synthesis of a layered medium from its acoustic transmission response, Geophysics, 33, 264-269, 1968.

Gibson, B., K. Larner, and S. Levin, Efficient 3-D Migration in two steps, Geophys. Prospect., 31, 1-33, 1983.

Horie, S. and S. Tanaka, Multichannel seismic profiles, Paleolim. Lake Biwa Jpn. Plei., 11, 57-99, 1983.

Horie, S., S. Ishida, S. Nishimura, T. Yokoyama, and H. Taishi, The studies on deposition in the deep part of the Kobiwako group, The Report of investigation of a natural gas reservoir in Shiga prefecture, Shiga Prefecture, 16-57, 1981 (in Japanese).

Horike, M., Inversion of phase velocity of long period microtremors to the S-wave velocity structure down to the basement in urbanized areas, J. Phys. Earth, 33, 59-96, 1985.

Ikawa, T., Seismic survey to the depth of $2,000 \mathrm{~m}$ in Lake Biwa, in The History Recorded in the Sedimentary Layers Under Lake Biwa down to 1,400 m of the Depth, ed. S. Horie, pp. 1-284, Dohosha, Kyoto, 1988 (in Japanese).

Irikura, K. and J. Akamatsu, Earthquake motions observed on ground and rock, Bull. Disas. Prev. Res. Inst. Kyoto Univ., 24, 263-280, 1974.

Kasuga, S., Observed amplitude variations of microtremors in the neighborhood of buried faults, Prog. Abstr., Seismol. Soc. Jpn., 2, 190, 1983 (in Japanese).

Nishikawa, K., T. Nishibori, T. Kobayakawa, T. Tajima, M. Joshima, K. Mimura, and M. Katada, Koto Rhyolite and its activity, Southwest Japan, J. Assoc. Miner., Petrol. Econ. Geol., 77, 51-64, 1983 (in Japanese).

Nishimura, K. and W. Morii, Azimuthal deflection of P-wave Initial motion observed at the Osakayama Crustal Deformation Observatory, Shiga Prefecture, Zisin, Ser. 2, 38, 137-140, 1985 (in Japanese).

Nishimura, S., Gravity survey in Shiga prefecture, nature in Shiga Prefecture, 475, 1979.

Research Group of Seismicity around Lake Biwa, On the activity of earthquakes in the area around Lake Biwa, Bull. Disas. Prev. Res. Inst. Kyoto Univ., 20 B-1, 21-28, 1977 (in Japanese). 
Robinson, E. A., Predictive decomposition of seismic traces, Geophysics, 22, 767-778, 1957.

Robinson, E. A., Multichannel Time Series Analysis with Digital Computer Programs, Holden-Day, San Francisco, 1967.

Scherbaum, F., Seismic imaging of the site response using micro-earthquake recordings. Part I. Method, Bull. Seismol. Soc. Am., 77, 1905-1924, 1987a.

Scherbaum, F., Seismic imaging of the site response using micro-earthquake recordings. Part II. Application to the Swabian Jura, Southwest Germany, Seismic Network, Bull. Seismol. Soc. Am., 77, 1925-1944, 1987 b.

Scherbaum, F. and D. Stoll, The estimation of Green's function from local earthquake recordings and the modeling of the site response, Phys. Earth Planet. Inter., 38, 189-202, 1985.

Shichi, R., The gravity survey for major active faults in Southwest Japan inner zone, in The Circular of the Project in the Southwest Japan Inner Zone, Vol. 18, pp. 1-5, 1990 (in Japanese).

Stolt, R. H., Migration by Fourier transform, Geophysics, 43, 23-28, 1978.

Sugimoto, T., Correlation of seismic velocities with lithology, in Handbook of Seismic Survey for Civil Engineering, ed. The Editorial Committee for Special Issues, pp. 374-403, The Society of Exploration Geophysicists of Japan, Kawasaki, 1977 (in Japanese).

Taishi, H., Y. Inouchi, and T. Meguro, Continuous seismic reflection subbottom profiling with "Uniboom" in the North basin of Lake Biwa, Geophys. Bull. Hokkaido Univ., 49, 251-268, 1987 (in Japanese).

Takemura, $\mathrm{K}$. and T. Yokoyama, Sedimentary facies of the $1,400 \mathrm{~m}$ drilling sample from Lake Biwa with reference to the discontinuity in the sedimentary sequence, IPPCCE Newsl., 5, 36-48, 1989.

Takemura, K., S. Nishimura, T. Danhara, and T. Yokoyama, Properties and Fission-track age of volcanic ashes in the $1,000 \mathrm{~m}$ core samples of Lake Biwa, with special reference to correlation by tephra among the $1,000,200 \mathrm{~m}$ boring core samples of Lake biwa and Kobiwako Group., Paleolim. Lake Biwa Jpn. Plei., 4, 79-95, 1976.

The Research Group for Active Faults, Active Faults in Japan, The University of Tokyo Press, Tokyo, 1980 (in Japanese).

Tsutsui, T., Pseudo-Reflection Profiling method: an efficient complement to CDP method, Geophy. Prospect., 1990 (in press).

Tsutsui, T. and Y. Kobayashi, Discontinuity of basement rock depth in eastern coast of Lake Biwa, discovered by observations of microseisms, J. Phys. Earth, 37, 133-146, 1989.

Tsutsui, T., Y. Kobayashi, Y. Shiba, Y. Suda, Y. Murai, T. Iwata, H. Fujiwara, and I. Matsui, Exploration of subsurface structure around the estuary of Hino River, southeast shore of Lake Biwa, by means of seismic reflection survey, Zisin, Ser. 2, 42, 405-418, 1989 (in Japanese).

Yanovskaya, T. B. and Y. V. Roslov, Peculiarities of surface wave fields in laterally inhomogeneous media in the framework of ray theory, Geophys. J. Int., 99, 287-303, 1989.

Yokoyama, T., Tectonic development of Nanko Basin, southern part of Lake Biwa, Central Japan, Paleolim. Lake Biwa Jpn. Plei., 7, 115-134, 1979.

Yokoyama, T. and T. Takemura, Geologic column obtained by the deep drilling from the bottom surface of Lake Biwa, Japan, IPPCCE Newsl., 3, 21-23, 1983.

Yokoyama, T., C. Matsuoka, and M. Tamura, On the Plio-Pleistocene Kobiwako group, Nature in Shiga Prefecture, 309-389, 1979 (in Japanese).

Yokoyama, T., S. Ishida, T. Danhara, S. Hashimoto, T. Hayashi, A. Hayashida, Y. Nakagawa, T. Nakajima, N. Natuhara, J. Nishida, Y. Otofuji, M. Sakamoto, K. Takemura, N. Tanaka,

Vol. 38, No. 6, 1990 
M. Torii, K. Yamada, S. Yoshikawa, and S. Horie, Lithofacies of the $1,000 \mathrm{~m}$ core samples on the east coast of Lake Biwa, Japan, Paleolim. Lake Biwa Jpn. Plei., 4, 58, 1976.

\section{APPENDIX}

\section{Pseudo-Reflection Profiling Method}

Claerbout (1968) derived a fundamental equation for Pseudo-Reflection Profiling method. The equation implies the causal part of the autocorrelation function of the response to a transmitted impulse $X(z)$ on the surface is identified with a zero offset reflection seismogram $1+R(z)$. This equation is expressed as a $Z$-transform:

$$
(1+R(z)+R(1 / z)) \Pi d e t=X(z) X(1 / z),
$$

where $\Pi$ det is a constant determined by the reflection and transmission coefficients of reflectors. This equation is called the Claerbout-Kunetz equation.

Actually in explosion experiments, even if the source wavelet were impulsive, the waveform of the incident wavelet at the bottom of a site can be a complicated one affected by complexities of the propagation path and inelasticity. In that case the observed $D_{i}(z)$ for the $i$ th station on the surface of the site will be

$$
D_{i}(z)=X_{i}(z) Y(z) \text {, }
$$

where $Y(z)$ is the incident wavelet at the bottom of the medium.

$X_{i}(z)$ must be isolated from the observed seismogram $D_{i}(z)$ before application of Eq. (A.1). Scherbaum $(1987 \mathrm{a}, \mathrm{b})$ invoked the Initial Phase Window technique (Scherbaum and Stoll, 1985) to derive the equivalent incident wavelet $Y(z)$ from seismograms, assuming the incident wavelet to be almost impulsive.

In this study, a new technique, the Reference-Station technique (Fig. A1) is proposed to cope with the cases when the path and source effects to the incident wavelet can be

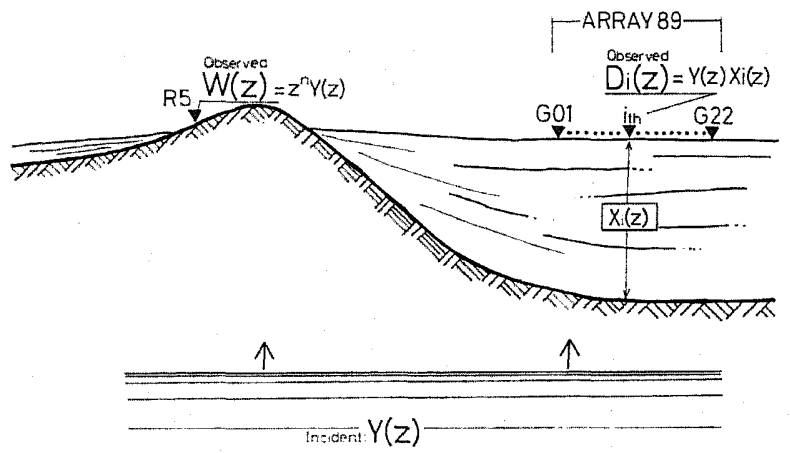

Fig. A1. Illustration for obtaining transmission response for stations on soft deposits through the Reference-Station technique. Station R5 is deployed on the basement rock. Other stations G1-G22 in ARRAY 89 are set on soft deposits. $X_{i}(z)$ is a transmission response in $Z$-transform for the $i$ th station. 


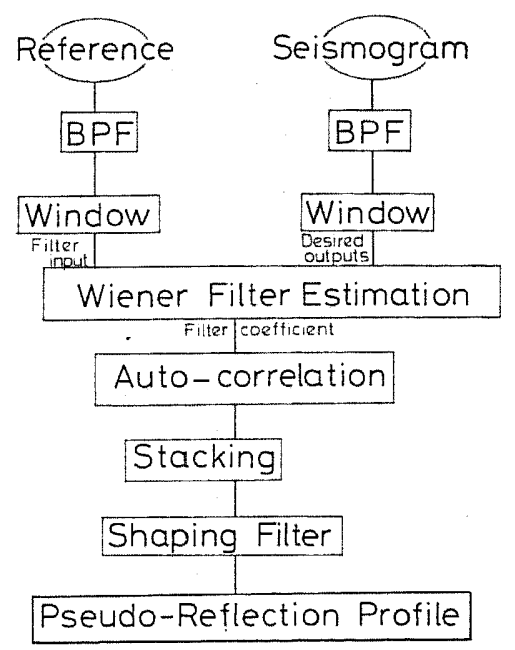

Fig. A2. Processing flow diagram for PRP method.

more significant than those in Scherbaum (1987 a, b). It is assumed that the equivalent incident wavelet $Y(z)$ may be derived from a seismogram $W(z)$ on the basement rock nearby (e.g., station R5), through

$$
W(z)=z^{n} Y(z) .
$$

Equation (A.3) is substituted into (A.2), and

$$
D_{i}(z)=z^{-n} X_{i}(z) W(z)
$$

is obtained.

$X(z)$ is deconvolved through solving Eq. (A.4) by using $D_{i}(z)$ and $W(z)$. To this end, the statistical deconvolution by the Wiener filtering (Robinson, 1967) is employed; $W(z)$ and $D_{i}(z)$ are the input and the desired output of the filter, respectively, and the filter coefficients to be obtained are equivalent to the transmission response, $z^{-n} X_{i}(z)$.

The advanced impulse response $z^{-n} X_{i}(z)$ is substituted into Eq. (A.1), and then the final profile is obtained after shaping filtering applied if necessary. The flow chart of the total process is shown in Fig. A2.

Vol. 38, No, 6, 1990 